\title{
Mesenchymal stromal cells in bone marrow express adiponectin and are efficiently targeted by an adiponectin promoter-driven $\mathrm{Cre}$ transgene
}

\section{AUTHOR(S):}

Mukohira, Hisa; Hara, Takahiro; Abe, Shinya; TaniIchi, Shizue; Sehara-Fujisawa, Atsuko; Nagasawa, Takashi; Tobe, Kazuyuki; Ikuta, Koichi

\section{CITATION:}

Mukohira, Hisa ... [et al]. Mesenchymal stromal cells in bone marrow express adiponectin and are efficiently targeted by an adiponectin promoter-driven Cre transgene. International immunology 2019, 31(11): 729-742

\section{ISSUE DATE:}

2019-11

\section{URL:}

http://hdl.handle.net/2433/253542

\section{RIGHT:}

This is a pre-copyedited, author-produced version of an article accepted for publication in International immunology following peer review. The version of record Hisa Mukohira, Takahiro Hara, Shinya Abe, Shizue Tani-ichi, Atsuko SeharaFujisawa, Takashi Nagasawa, Kazuyuki Tobe, Koichi Ikuta, Mesenchymal stromal cells in bone marrow express adiponectin and are efficiently targeted by an adiponectin promoter-driven Cre transgene, International Immunology, Volume 31, Issue 11, November 2019, Pages 729-742 is available online at: https://doi.org/10.1093/intimm/dxz042.; の論文は出版社版でありません。引用の際には出版社版をご確認ご利用ください。; This is not the published version. Please cite only the published version. 


\title{
Mesenchymal Stromal Cells in Bone Marrow Express Adiponectin and Are Efficiently Targeted by an Adiponectin Promoter-Driven Cre Transgene
}

\author{
Hisa Mukohira, ${ }^{1,2}$ Takahiro Hara, ${ }^{1}$ Shinya Abe, ${ }^{1,2}$ Shizue Tani-ichi, ${ }^{1,3}$ \\ Atsuko Sehara-Fujisawa, ${ }^{4}$ Takashi Nagasawa, ${ }^{5}$ Kazuyuki Tobe,${ }^{6}$ \\ and Koichi Ikuta ${ }^{1}$
}

${ }^{1}$ Laboratory of Immune Regulation, Department of Virus Research, Institute of Frontier Life and Medical Sciences, Kyoto University, Kyoto 606-8507, Japan; ${ }^{2}$ Graduate School of Medicine, Kyoto University, Kyoto 606-8501, Japan; ${ }^{3}$ Laboratory of Biological Chemistry, Human Health Sciences, Graduate School of Medicine, Kyoto University, Kyoto 606-8507, Japan; ${ }^{4}$ Laboratory of Tissue Stem Cell Biology, Department of Regeneration Science and Engineering, Institute of Frontier Life and Medical Sciences, Kyoto University, Kyoto 606-8507; ${ }^{5}$ Laboratory of Stem Cell Biology and Developmental Immunology, Graduate School of Frontier Biosciences and Graduate School of Medicine, Osaka University, Osaka 565-0871, Japan; ${ }^{6}$ First Department of Internal Medicine, Faculty of Medicine, University of Toyama, Toyama 930-0194, Japan.

Correspondence:

Koichi Ikuta

Tel.: +81 75751 4012; Fax: +81 75751 4810; E-mail: ikuta.koichi.6c@kyoto-u.ac.jp 


\section{Abstract}

Stromal cells in bone marrow (BM) constitute a specific microenvironment supporting development and maintenance of hematopoietic cells. Adiponectin is a cytokine secreted by adipocytes. Besides its anti-diabetic and anti-atherogenic roles, adiponectin reportedly regulates development and function of hematopoietic cells in BM. However, it remains unclear whether mesenchymal stromal cells in BM express adiponectin. Here, we show that PDGFR $\beta^{+} \mathrm{VCAM}-1^{+}$stromal cells express adiponectin. Lineage tracing revealed that a majority of PDGFR $\beta^{+} \mathrm{VCAM}-1^{+}$cells were targeted by an adiponectin promoter-driven Cre (Adipoq-Cre) transgene. Additionally, the Adipoq-Cre transgene targets a minority of osteoblasts at younger age but larger populations are targeted at older age. Furthermore, the Adipoq-Cre transgene targets almost all of CXCL12-abundant reticular (CAR) cells and that most of the stromal cells targeted by the Adipoq-Cre transgene are CAR cells. Finally, deletion of interleukin-7 (IL-7) by the Adipoq-Cre transgene resulted in severe impairment of B lymphopoiesis in BM. These results demonstrate that PDGFR $\beta^{+} \mathrm{VCAM}-1^{+}$stromal cells in BM express adiponectin and are targeted by the Adipoq-Cre transgene, suggesting broader specificity of Adipoq-Cre transgene.

Keywords: adipocyte, adiponectin, bone marrow, CXCL12, IL-7, stromal cells 


\section{Introduction}

Bone marrow (BM) microenvironment is constituted of several types of mesenchymal stromal cells. First, CXCL12-GFP knock-in mice revealed robust GFP-expressing mesenchymal stromal cells, known as CXCL12-abundant reticular (CAR) cells. CAR cells support hematopoietic stem cell (HSC) maintenance by secreting CXCL12 and stem cell factor (SCF), and B lymphopoiesis by secreting interleukin-7 (IL-7) (1-4). Second, arteriolar NG2 ${ }^{+}$cells maintain HSCs by producing CXCL12 but not SCF (5). Finally, while CAR cells are Ter119-CD45 ${ }^{-}$Sca- $1^{-}$PDGFR $\alpha^{+}$cells, Ter1 $19^{-} \mathrm{CD}^{-} 5^{-} \mathrm{Sca}^{-} 1^{+} \mathrm{PDGFR}^{+}$stromal cells, referred to as $\mathrm{P} \alpha \mathrm{S}$, are distributed primarily around arterioles (6). Mesenchymal stromal cells were identified by their expression of nestin-GFP, leptin receptor (Lepr), and Prx1-Cre, but the subsets defined by different markers appear to overlap with each other $(7,8)$. Furthermore, mesenchymal stromal cells in BM have potential to differentiate into osteoblasts, adipocytes, and chondrocytes in vitro (9). It remains controversial how and where HSC self-renewal and differentiation are maintained in BM microenvironment.

Adiponectin (Adipoq) is one of the cytokines secreted by adipocytes. Adiponectin enhances insulin sensitivity by increasing glucose uptake and fatty acid oxidation in liver and muscle (10-13). In addition, adiponectin plays roles in immunity: adiponectin inhibits proliferation of myelomonocytic and early B lymphoid cells, suppresses functions of macrophages and NK cells, and increases HSC proliferation (14-18). Later, it is reported that adiponectin is expressed also in osteoblasts and $\mathrm{Lepr}^{+}$stromal cells in BM $(19,20)$. However, these reports are inconsistent with the observation that Adipoq-Cre BAC transgene is expressed specifically in adipose tissue of Adipoq-Cre transgenic mice (21-28). Therefore, it is still uncertain whether BM stromal cells secrete adiponectin. 
In this study, we showed that PDGFR $\beta^{+} \mathrm{VCAM}-1^{+}$stromal cells in BM express adiponectin transcripts, and a majority of PDGFR $\beta^{+} \mathrm{VCAM}-1^{+}$stromal cells were targeted by an Adipoq-Cre transgene. Consistently, the Adipoq-Cre transgene targets almost all of CAR cells in BM. Furthermore, B cell development was severely impaired in BM of IL- $7^{\mathrm{f} / \mathrm{f}}$ Adipoq-Cre mice. Thus, our study demonstrates that adiponectin transcripts is specifically expressed in PDGFR $\beta^{+}$VCAM- $1^{+}$stromal cells in addition to adipocytes. 


\section{Methods}

\section{Mice}

C57BL/6 mice were purchased from Japan SLC (Hamamatsu, Japan). Adipoq-Cre, R26 ${ }^{\text {tdomato, }}$ $\mathrm{R} 26^{\mathrm{YFP}}, \mathrm{CXCL} 12^{\mathrm{GFP}}, \mathrm{IL}-7^{\mathrm{GFP}}$ and $\mathrm{IL}^{-7^{\mathrm{fl}}}$ mice were reported previously $(1,21,29-31)$. These mouse lines were on C57BL/6 backgrounds. Mice were maintained under specific pathogen-free conditions in the Experimental Research Center for Infectious Diseases in the Institute for Frontier Life and Medical Sciences, Kyoto University. All mouse protocols were approved by the Animal Experimentation Committee of the Institute for Frontier Life and Medical Sciences, Kyoto University.

\section{Antibodies (Abs) and flow cytometry}

Flow cytometry and cell sorting were performed on a FACS Verse flow cytometer and a FACS Aria III cell sorter (BD Biosciences, Franklin Lakes, NJ) and analyzed with the FlowJo software (TreeStar, Ashland, OR). The following monoclonal antibodies (mAbs) (clone name in parentheses) were used: FITC-anti-CD31 (MEC13.3), PE-Cy7-anti-Sca-1 (E13-161.7), Brilliant Violet (BV) 421-anti-CD31 (390), BV421-anti-Sca-1 (D7), APC-anti-VCAM-1 (429), PE-anti-VCAM-1 (429), APC-Cy7-anti-CD45 (30-F11), APC-Cy7-anti-Ter119, biotin-anti-PDGFR $\beta$ (APB5), anti-Cre (7-23), anti-alkaline phosphatase (ALPL) (Phe18-Gly503), FITC-anti-CD19 (6D5), PE-anti-Flt3 (A2F10), PE-Cy7-anti-IgD (11-26c.2a), APC-anti-c-Kit (2B8), BV421-anti-IgM (RMM-1), $\quad$ FITC-anti-EpCAM (G8.8), APC-anti-Ly51 (6C3), FITC-anti-CD3 $\varepsilon \quad(145-2 C 11), \quad$ PE-anti-NK1.1 (PK136), PE-Cy7-anti-CD45.2 (104), APC-CD1d tetramer loaded with PBS-57, APC-anti-CD19 (MB19-1), APC-Cy7-anti-CD4 (RM4-5), eFluor 450-anti-CD8 (53-6.7), and APC-anti-mouse IgG1 (RMG1-1). Abs were obtained from BioLegend (San Diego, CA), R\&D Systems 
(Minneapolis, MN), eBioscience (San Diego, CA), TONBO (Tokyo, Japan), and Merck (Darmstadt, Germany) except for APC-CD1d tetramer, which was a kind gift from NIH Tetramer Core Facility at Emory University. PE-Cy7-streptavidin, BV421-streptavidin, and Alexa Fluor 647-anti-goat IgG were purchased from BioLegend, eBioscience, and Invitrogen (Carlsbad, CA), respectively. Intracellular staining was done using the Foxp3 Staining Buffer Set according to the manufacturer's instructions (eBioscience).

\section{Isolation of BM cells}

For analysis of lymphocytes in BM, cells were isolated by flushing femurs. Red blood cells were lysed with ammonium chloride potassium buffer. For analysis of stromal cells in the inner compartment of bone marrow (I-BM), tibias and femurs were flushed with using $1 \mathrm{ml}$ of RPMI 1640 medium containing $200 \mathrm{U} / \mathrm{ml}$ collagenase IV (Worthington Biochemical Corporation, Lakewood, NJ) and 100 U/ml DNase I (Sigma-Aldrich, St. Louis, MO). The flushed marrow was digested at $37^{\circ} \mathrm{C}$ for $40 \mathrm{~min}$. Ter $119^{+}$and $\mathrm{CD} 45^{+}$cells were then depleted using anti-Ter119 and CD45 microbeads and LD Columns (Miltenyi Biotec, Bergisch Gladbach, Germany). For analysis of osteoblasts associated with the endosteal surface of bone marrow (E-BM), marrow-flushed bones were crushed with a pestle and incubated in the same solution as above at $37^{\circ} \mathrm{C}$ for $10 \mathrm{~min}$. The incubation was repeated three times and then filtered through a $40 \mu \mathrm{m}$ cell strainer. For analysis of adipocytes in caudal vertebrae (CV), CV were dissected under a stereo microscope and crushed with a pestle and incubated in the same solution as above at $37^{\circ} \mathrm{C}$ for $40 \mathrm{~min}$. The cell suspension was filtered through a $100 \mu \mathrm{m}$ cell strainer and centrifuged at $380 \times \mathrm{g}$ for $4 \mathrm{~min}$ at room temperature. Floating cell layer was collected as CV adipocytes.

\section{Isolation of adipocytes and stromal vascular fraction (SVF) from adipose tissue}


Mice were perfused with $25 \mathrm{ml}$ of phosphate-buffered saline (PBS) containing $25 \mathrm{mM}$ EDTA. Perigonadal and mesenteric fat pads were cut into pieces with scissors and incubated at $37^{\circ} \mathrm{C}$ for $1 \mathrm{hr}$ in $1 \mathrm{ml}$ of RPMI 1640 medium containing $200 \mathrm{U} / \mathrm{ml}$ collagenase IV and $100 \mathrm{U} / \mathrm{ml}$ DNase I (Sigma-Aldrich, St. Louis, MO). The cell suspension was filtered through a $100 \mu \mathrm{m}$ cell strainer and centrifuged at $380 \times \mathrm{g}$ for $4 \mathrm{~min}$ at room temperature. Floating cell layer and cell pellet were collected as adipocytes and the SVF cells, respectively.

\section{Enrichment of thymic stromal cells}

Mice were perfused with $25 \mathrm{ml}$ of PBS containing $25 \mathrm{mM}$ EDTA. Thymus was cut into pieces with scissors and incubated at $37^{\circ} \mathrm{C}$ for $1 \mathrm{hr}$ in $1 \mathrm{ml}$ of RPMI 1640 medium containing 200 $\mathrm{U} / \mathrm{ml}$ collagenase IV and $100 \mathrm{U} / \mathrm{ml}$ DNase I. The cell suspension was filtered through a $70 \mu \mathrm{m}$ cell strainer, and CD45 ${ }^{+}$cells were then depleted using CD45 microbeads and LD Columns.

\section{Real-time RT-PCR}

Total RNA was extracted with Sepasol reagent (Nacalai Tesque, Kyoto, Japan), and reverse transcribed using ReverTra Ace (Toyobo, Osaka, Japan) with oligo(dT) ${ }_{12-18}$ primer. cDNA was amplified in duplicate on a StepOnePlus Real-Time PCR System (Thermo Fisher Scientific, Waltham, MA) with a QuantiTect SYBR Green PCR Kit (Qiagen, Hilden, Germany) and ROX reference dye (Invitrogen). PCR was carried out initially at $95^{\circ} \mathrm{C}$ for 15 sec and then 45 cycles of $95^{\circ} \mathrm{C} 20 \mathrm{sec}, 55^{\circ} \mathrm{C} 30 \mathrm{sec}$, and $72^{\circ} \mathrm{C} 1 \mathrm{~min}$. After amplification, melting curve analysis was performed to verify the specificity of the reaction. PCR efficiency was normalized using cDNA of isolated adipocytes from wild-type perigonadal adipose tissue (PAT) as a standard for real-time PCR. Transcript levels were normalized to hypoxanthine-guanine phosphoribosyltransferase (HPRT) mRNA. Primer sequences are as follows: Adipoq (adiponectin), 5'-TGAGACCTGGCCACTTTCTC-3' and 
5'-TGGGCAGGATTAAGAGGAAC-3';

Plin1

(perilipin),

5'-CTGTGGTACACTATGTGCCG-3' and 5'-GCTGAAGGGTTATCGATGTC-3'; and Hprt (HPRT), 5'-GTTGGATACAGGCCAGACTTTGTTG-3'

and 5'-GATTCAACTTGCGCTCATCTTAGGC-3'.

\section{Immunohistochemistry}

Freshly dissected tissues were fixed in $4 \%$ paraformaldehyde at $4^{\circ} \mathrm{C}$ for $6 \mathrm{hr}$, followed by 3-day dehydration in a solution of $10 \%, 20 \%$ and $30 \%$ sucrose in PBS at $4{ }^{\circ} \mathrm{C}$ overnight. Samples were embedded in Optimal Cutting Temperature compound (Sakura Finetechnical, Tokyo, Japan) and frozen in cooled hexane. Sections ( $8 \mu \mathrm{m}$ thick) were prepared according to the Kawamoto method (32). Sections were rehydrated in PBS for 5 min and blocked with PBS containing $0.05 \%$ Tween, 20.1\% BSA and 5\% mouse serum at room temperature for $1 \mathrm{hr}$ before staining. Primary Abs were applied to the slides at room temperature for $1.5 \mathrm{hr}$, followed by secondary $\mathrm{Ab}$ incubation at room temperature for $30 \mathrm{~min}$. Anti-GFP (Invitrogen), anti-S100 (Dako, Santa Clara, CA), anti-perilipin (Abcam, Cambridge, UK), anti-ALPL (R\&D Systems) and biotin-anti-VCAM-1 (a kind gift of Dr. Tatsuo Kina at Kyoto University) were used as the first Abs. DyLight 488-anti-rabbit IgG (BioLegend), DyLight 649-anti-rabbit IgG (BioLegend), Alexa Fluor 647-anti-goat IgG (Invitrogen) and BV421-streptavidin (eBioscience) were used as the second Abs. Alexa Fluor 488-anti-Sca-1, FITC-anti-EpCAM, and APC-anti-Ly51 (all from BioLegend) were also used. For nuclear staining, sections were treated with DAPI. Sections were washed with PBS between Ab incubations. Stained sections were mounted with PermaFluor Aqueous Mounting Medium (Thermo Fisher Scientific, Waltham, MA). Images were acquired on a Leica SP8 confocal microscope.

\section{Statistical analysis}


For all bar graphs, data are shown as means \pm SEM. Comparisons between two samples were performed using the unpaired two-tailed Student's $t$-test. One-way ANOVA analyses followed by Tukey's multiple-comparisons test and two-way ANOVA analyses were used for multiple group comparisons. Statistical analyses were performed using the GraphPad Prism 7 software. Asterisks in all figures indicate the following: *, $p<0.05 ; * *, p<0.01 ; * * *, p<0.001 ;$ n.s., not significant. 


\section{Results}

\section{PDGFR $\beta^{+} V C A M-1^{+}$stromal cells in BM express adiponectin transcripts}

To investigate whether BM cells express adiponectin, we compared adiponectin transcripts in subpopulations of BM with those in adipocytes of PAT. We isolated Ter119- CD45-CD31 ${ }^{-} \mathrm{Sca}-1^{-} \mathrm{PDGFR} \beta^{+} \mathrm{VCAM}^{-}{ }^{+}$cells, blood vascular endothelial cells (BECs), other stromal cells, and $\mathrm{CD} 45^{+}$hematopoietic cells from wild-type BM of femurs and tibias by flow cytometry to measure adiponectin transcripts by real-time RT-PCR (Fig. 1A). To isolate adipocytes from BM, we took advantage of a gradient of adiposity in mouse vertebrae (33). Thoracic vertebrae (TV) and sacral vertebrae (SV) appeared red, whereas caudal vertebrae (CV) looked white (Fig. 1B). The mRNA levels of perilipin, a lipid droplet-associated protein, in the whole CV were significantly higher than the whole TV and SV (Fig. 1C). These results imply that CV contain a much greater number of adipocytes than TV and SV. At 8 weeks old, levels of adiponectin transcripts in PDGFR $\beta^{+}$VCAM- $1^{+}$cells were twofold higher than in PAT adipocytes and 20-fold higher than in CV adipocytes (Fig. 1D). By contrast, levels of adiponectin transcripts in BECs, other stromal cells, and hematopoietic cells were lower by 7-, 700-, and 2,500-fold, respectively, than PAT mature adipocytes. As for perilipin expression, all the subpopulations of BM including PDGFR $\beta^{+} \mathrm{VCAM}-1^{+}$cells and $\mathrm{CV}$ adipocytes represented much lower levels of perilipin transcripts than PAT adipocytes (Fig. 1D). In addition, flow cytometric analysis revealed that 93\% of PDGFR $\beta^{+}$VCAM- $1^{+}$cells expressed Cre recombinase in Adipoq-Cre mice at 8 weeks old, although hematopoietic cells and other BM stromal cells did not (Fig. 1E and F). Similar pattern of adiponectin mRNA expression was observed at 4 weeks old (Supplementary Figure 1A). We also observed that $85 \%$ of PDGFR $\beta^{+} \mathrm{VCAM}-1^{+}$cells expressed Cre recombinase in Adipoq-Cre mice at 4 weeks old (Supplementary Figure 1B and C). These results indicate that 
PDGFR $\beta^{+} \mathrm{VCAM}-1^{+}$stromal cells in BM express adiponectin at high levels both at 8 and 4 weeks old.

\section{An Adipoq-Cre transgene targets a majority of PDGFR $\beta^{+} V C A M-1^{+}$stromal cells in bone marrow}

Because adiponectin was expressed in PDGFR $\beta^{+} \mathrm{VCAM}-1^{+}$stromal cells, we asked whether an Adipoq-Cre transgene targets these cells. To define the targeting specificity of the Adipoq-Cre transgene, we generated Adipoq-Cre ${ }^{+} ; \mathrm{R}_{2} 6^{\text {tdTomato/+ }}$ mice. The $\mathrm{R}^{\text {tdTomato }}$ allele permits identification of Adipoq-Cre-targeted Tomato ${ }^{+}$cells. We separately examined the cells in the inner compartment of BM (I-BM) and those associated with the endosteal surface of BM (E-BM) at 8 weeks old. We checked Tomato expression in PDGFR $\beta^{+}$VCAM- $1^{+}$ stromal cells, CD $31^{+} \mathrm{Sca}-1^{+} \mathrm{BECs}, \mathrm{CD} 31^{-} \mathrm{Sca}-1^{+}$stromal cells, and other stromal cells in I-BM, and also in osteoblasts, BECs, and $\mathrm{CD}^{-} 1^{-} \mathrm{Sca}-1^{+}$stromal cells in E-BM of Adipoq-Cre ${ }^{+}$; R26 $6^{\text {tdTomato/+ }}$ femurs and tibias (Fig. 2A and B). Interestingly, we observed that the Adipoq-Cre transgene targets $94 \%$ of PDGFR $\beta^{+} \mathrm{VCAM}-1^{+}$cells but less than $10 \%$ of any other stromal cell populations at 8 weeks old (Fig. 2C). Additionally, most of Adipoq-Cre-targeted PDGFR $\beta^{+} \mathrm{VCAM}-1^{+}$cells expressed Cre recombinase, and vice versa (Fig. 2D), suggesting that $\mathrm{PDGFR} \beta^{+} \mathrm{VCAM}-1^{+}$cells are homogenous with regard to adiponectin expression.

Next, we employed immunostaining to detect Tomato expression in Adipoq-Cre ${ }^{+}$; R26 $6^{\text {tdTomato// }}$ mice. To assess targeting of the cells in I-BM, we stained bone sections with Abs against S100 and Sca-1 to detect mesenchymal stromal cells and arteriolar endothelial cells, respectively. Tomato ${ }^{+}$cells largely co-expressed S100 but not Sca-1 in I-BM (Fig. 3A). Next, we stained E-BM bone sections with Abs against alkaline phosphatase (ALP) to detect osteoblasts. Tomato ${ }^{+}$cells rarely co-expressed ALP or Sca-1 in E-BM (Fig. 3B). Finally, we 
stained bone sections and mesenteric adipose tissue with Abs against perilipin. Some Tomato ${ }^{+}$ cells co-expressed perilipin in BM, and most Tomato $^{+}$cells co-expressed perilipin in adipose tissue (Fig. 3C and Supplementary Figure 2). These results indicate that Adipoq-Cre transgene targets a majority of $\mathrm{PDGFR} \beta^{+} \mathrm{VCAM}-1^{+}$stromal cells but a minority of other stromal cell populations in BM at 8 weeks old. In addition, although the expression level of adiponectin in BM adipocytes is lower than that in PAT adipocytes (Fig. 1D), Adipoq-Cre transgene targets adipocytes in BM. To confirm the accuracy of Adipoq-Cre targeting with a different fluorescent protein, we generated Adipoq-Cre ${ }^{+}$: R2 $6^{\mathrm{YFP} /+}$ mice. We checked YFP expression in $\mathrm{PDGFR} \beta^{+} \mathrm{VCAM}-1^{+}$stromal cells in I-BM and in osteoblasts in E-BM of Adipoq-Cre ${ }^{+}$; $26^{\mathrm{YFP} /+}$ femurs and tibias (Supplementary Figure 3A and B). The percentages

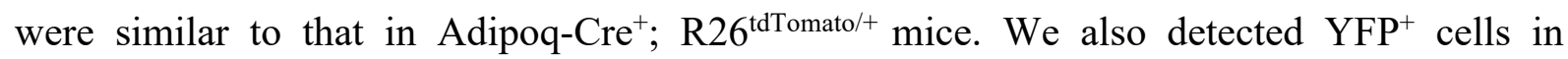
Adipoq-Cre ${ }^{+}$; R26 ${ }^{\mathrm{YFP} /+}$ BM sections with similar results (Supplementary Figure 3C).

Thymus contains some adipocyte precursors (34-36), and number of adipocytes increases during thymic involution (37-39). Thus, we next examined Tomato expression in thymus, which contains thymic epithelial cells (TECs) and mesenchymal stromal cells. Flow cytometric analysis showed that the Adipoq-Cre transgene targets $4.5 \%$ of TECs but only $0.06 \%$ of $\mathrm{EpCAM}^{-}$stromal cells at 8 weeks old (Supplementary Figure 4A and B), and 5.1\% of TECs and $0.1 \%$ of EpCAM ${ }^{-}$stromal cells at 24 weeks old (Supplementary Figure 4B). Immunofluorescence staining showed Tomato $^{+}$cells exist exclusively in thymic medulla (Supplementary Figure 4C). These data suggest that the Adipoq-Cre targets a minority of medullary TECs (mTECs) in thymus.

Secondary lymphoid organs contain stromal cells, which support homeostasis and response of lymphocytes. Splenic stromal cells include $\mathrm{VCAM}-1^{+} \mathrm{ICAM}-1^{+}$cells and MAdCAM-1 ${ }^{+}$marginal reticular cells (40), whereas lymph node stromal cells include gp $38^{+} \mathrm{CD} 31^{-}$fibroblastic reticular cells and gp $38^{+} \mathrm{CD} 31^{+}$lymphatic endothelial cells (LECs) 
(41). To assess targeting of the cells in secondary lymphoid organs, we performed immunostaining to detect Tomato expression in spleen and mesenteric lymph nodes (mLNs) of Adipoq-Cre ${ }^{+} ; \mathrm{R}_{2} 6^{\text {tdTomato/+ }}$ mice. We rarely detected Tomato $^{+}$cells either in spleen or mLNs (Supplementary Figure 4D and E). This observation suggests that there are few Adipoq-Cre-targeted cells in spleen or mLNs.

A majority of the BM stromal cells targeted by the Adipoq-Cre transgene are

\section{CXCL12-abundant reticular cells}

To further characterize targeting specificity of the Adipoq-Cre transgene in BM, we generated Adipoq-Cre ${ }^{+}$; $26^{\mathrm{tdTomato} /+}$; $\mathrm{Cxcl1} 2^{\mathrm{GFP} /+}$ mice. The $\mathrm{Cxcl1} 2^{\mathrm{GFP} /+}$ transgene permits identification of CAR cells. We examined Tomato and GFP expression in BM of Adipoq-Cre ${ }^{+}$; R26 $6^{\text {tdTomato/+}}$; Cxcl12 $2^{\mathrm{GFP} /+}$ mice at 8 weeks old by flow cytometry. Almost all CAR cells were targeted by Adipoq-Cre (Fig. 4A and B), and most Adipoq-Cre-targeted Tomato ${ }^{+}$cells were CAR cells (Fig. 4C and D). Immunofluorescence staining also showed that $\mathrm{GFP}^{+} \mathrm{CAR}$ cells mostly co-expressed Tomato (Fig. 4E). These results indicate that a majority of Adipoq-Cre-targeted stromal cells in BM are CAR cells at 8 weeks old.

The Adipoq-Cre transgene targets PDGFR $\beta^{+} V C A M-1^{+}$stromal cells and osteoblasts in an age-dependent manner

To investigate whether targeting specificity of the Adipoq-Cre transgene changes with age, we examined Tomato expression in PDGFR $\beta^{+} \mathrm{VCAM}^{-}{ }^{+}$stromal cells and osteoblasts of Adipoq-Cre ${ }^{+}$R26 $6^{\text {tdTomato/+ }}$ mice at 4 and 24 weeks old by flow cytometry (Fig. 5A and B). The Adipoq-Cre transgene targeted $84 \%$ and $91 \%$ of PDGFR $\beta^{+} \mathrm{VCAM}-1^{+}$stromal cells and $1.4 \%$ and $21 \%$ of osteoblasts at 4 and 24 weeks old, respectively (Fig. 5C). We also observed by immunostaining that Tomato $^{+}$osteoblasts increased at 24 weeks old compared with 8 
weeks old (Fig. 5D). These results indicate that the Adipoq-Cre transgene targets PDGFR $\beta^{+}$VCAM- $1^{+}$stromal cells and osteoblasts in an age-dependent manner.

To further check the developmental onset of the Adipoq-Cre transgene, we performed immunostaining of Adipoq-Cre ${ }^{+} ; \mathrm{R}^{2} 6^{\mathrm{tdTomato} /+} \mathrm{BM}$ at postnatal day $0(\mathrm{P} 0), 1(\mathrm{P} 1), 2$ (P2) and 7 (P7). While Tomato $^{+}$cells were rarely detected in $\mathrm{BM}$ at $\mathrm{P} 0, \mathrm{Tomato}^{+}$cells were scattered throughout the BM at P7. Furthermore, there was a sharp increase in the number of Tomato ${ }^{+}$ cells by P1 (Fig. 5E and Supplementary Figure 5). These results suggest that Tomato $^{+}$cells emerge within one day after birth in BM of Adipoq-Cre ${ }^{+}$; $26^{\text {tdTomato/+ }}$ mice.

\section{Many of IL-7+ stromal cells in BM are targeted by the Adipoq-Cre transgene}

IL-7 is a cytokine important for lymphocyte development and homeostasis. Previous studies suggested that IL-7 produced by Lepr-Cre-targeted stromal cells plays an important role in B cell development in $\mathrm{BM}$ (1). We previously reported that $\mathrm{IL}^{\mathrm{GFP} /+}$ transgene allows identification of IL-7-producing cells (31). To investigate the relationship between IL-7 ${ }^{+}$ stromal cells and Adipoq-Cre-targeted cells, we generated Adipoq-Cre ${ }^{+} ; \mathrm{R}_{2} 6^{\text {tdTomato/+}} ;$ IL $7^{\mathrm{GFP} /+}$ mice. Flow cytometric analysis showed that $57 \%$ and $36 \%$ of $\mathrm{PDGFR}^{+} \mathrm{VCAM}^{+}{ }^{+}$stromal cells were Tomato $^{+} \mathrm{GFP}^{+}$and Tomato $^{+} \mathrm{GFP}^{-}$, respectively, at 8 weeks old (Fig. 6A). We also observed by immunostaining that many of Tomato $^{+}$cells co-expressed IL7-GFP (Fig. 6B). These results indicate that the Adipoq-Cre transgene targets many of IL-7-producing stromal cells in BM.

Next, we performed immunofluorescence staining to assess IL-7 expression in adipocytes in $\mathrm{IL} 7^{\mathrm{GFP} /+}$ mice, which the Adipoq-Cre transgene targets. Adipose tissue accounts for more than half of BM volume in elderly humans, whereas adipocytes are rare in adult murine BM, especially in long bones. We observed that adipocytes were more abundant in distal tibias than in proximal tibias, but that perilipin ${ }^{+}$adipocytes did not co-express GFP in any part of the 
$\mathrm{BM}$ in $\mathrm{IL}^{\mathrm{GFP} /+}$ mice (Supplementary Figure 6A). Furthermore, we did not detect IL7-GFP ${ }^{+}$ cells in mesenteric adipose tissue (Supplementary Figure 6B).

\section{B cell development is severely impaired in IL-7fff Adipoq-Cre mice}

We previously reported that IL-7 produced by PDGFR $\beta^{+}$VCAM- $1^{+}$stromal cells is essential for B cell development in BM (1). To assess whether Cre recombinase operates in BM of Adipoq-Cre mice, we generated IL- $7^{\mathrm{f} / \mathrm{f}}$ Adipoq-Cre mice and examined hematopoietic cells in BM by flow cytometry. The proportions of pro B, pre B, immature B, and mature B cells were significantly decreased in IL-7/f Adipoq-Cre mice (Fig. 7A and B). Absolute numbers of pro $\mathrm{B}$, pre $\mathrm{B}$, immature $\mathrm{B}$, and mature $\mathrm{B}$ cells were reduced by 17-, 37-, 14-, and 2-fold, respectively (Fig. 7B). The reduction of mature B cells was not as severe as B cell precursor subpopulations, probably because mature B cells survive and accumulate in periphery. By contrast, the proportions and absolute numbers of NK, NKT, invariant NKT (iNKT), T, $\mathrm{CD}^{-} \mathrm{CD}^{-}$double-negative (DN) $\mathrm{T}, \mathrm{CD} 8 \mathrm{~T}$, and $\mathrm{CD} 4 \mathrm{~T}$ cells were unchanged or slightly increased (Supplementary Figure 7A and B). These results suggest that B cell development is severely impaired because the Adipoq-Cre transgene has efficiently deleted IL-7 gene in mesenchymal stromal cells.

Because IL-7 produced by TECs is important for T cell development in the thymus (42), we examined whether thymocytes are affected in IL- $7^{\mathrm{f} / \mathrm{f}}$ Adipoq-Cre mice by flow cytometry. The proportions and absolute numbers of NKT, iNKT, DN, $\mathrm{CD} 8^{+} \mathrm{CD} 4^{+}$double-positive (DP), $\mathrm{CD} 8^{+} \mathrm{CD} 4^{-} \mathrm{SP}(\mathrm{CD} 8 \mathrm{SP})$, and $\mathrm{CD} 8^{-} \mathrm{CD}^{+} \mathrm{SP}$ (CD4 SP) cells were unchanged (Supplementary Figure $8 \mathrm{~A}$ and $\mathrm{B}$ ). This result is consistent with the observation that the Adipoq-Cre transgene targets only small proportion of TECs shown in Supplementary Figure 4B.

Finally, to investigate whether the disruption of BM microenvironment have some influence on lymphocytes in periphery, we examined PAT, mesenteric adipose tissue (MAT), 
spleen, and mesenteric lymph nodes (mLNs) of IL- $7^{\mathrm{f} / \mathrm{f}}$ Adipoq-Cre mice. In PAT, the proportions and absolute numbers of NK, NKT, CD4 T, CD8 T, and B cells were unchanged (Supplementary Figure 9). By contrast, in MAT, proportion of NK cells increased and that of B cells decreased. Absolute numbers of B, T, CD8 T, and CD4 T cells significantly decreased (Supplementary Figure 9). In spleen and mLNs, proportions of B cells decreased, whereas those of NK, NKT, CD8 T, and CD4 T cells were unchanged or slightly elevated (Supplementary Figure 10). Meanwhile, absolute numbers of B and CD8 T cells decreased, whereas those of NK, NKT, and CD4 T cells were unchanged in spleen and mLNs. These results suggest that the impairment of B cell development in BM of IL-7 $7^{\mathrm{f} / \mathrm{f}}$ Adipoq-Cre mice affects lymphocytes in peripheral lymphoid tissues in a tissue-dependent manner. 


\section{Discussion}

In this study, we show that PDGFR $\beta^{+} \mathrm{VCAM}-1^{+}$stromal cells in BM express adiponectin at high levels (Fig. 1). We also observe that the Adipoq-Cre transgene targets a majority of PDGFR $\beta^{+} \mathrm{VCAM}-1^{+}$stromal cells but less than $10 \%$ of any other stromal cell populations including BECs and osteoblasts at 8 weeks old (Fig. 2 and 3). In addition, we show that the Adipoq-Cre transgene targets almost all of CAR cells and that about $85 \%$ of the Adipoq-Cre-targeted stromal cells are CAR cells (Fig. 4). It is reported that Lepr-Cre transgene targets most of PDGFR $\beta^{+}$stromal cells and that $\mathrm{Lepr}^{+}$cells contribute to bone formation (43). We demonstrate that the proportion of osteoblasts targeted by the Adipoq-Cre transgene increases with age (Fig. 5). It is reported that BM stromal cells start to express the leptin receptor by P0 (43). As for adiponectin expression, we show that Adipoq-Cre-targeted cells drastically increase by P1 (Fig. 5). Finally, we observe that the Adipoq-Cre transgene targets many of IL-7-producing BM stromal cells (Fig. 6) and that IL-7 deletion by the Adipoq-Cre transgene severely impairs B cell development in BM (Fig. 7).

Because specific stromal cell populations regulate development and maintenance of distinct types of hematopoietic cells, it is important to validate the approaches to target specific stromal populations. Previous studies have shown that Prx1-Cre, Osx1-Cre, NG2-Cre, and Nes-GFP more broadly target BM stromal cells than Lepr-Cre $(3,5,44)$. Here, we revealed that Adipoq-Cre efficiently targets BM stromal cells besides adipocytes. In general, our results indicate that the specificity of Adipoq-Cre transgene in BM is similar to that of Lepr-Cre transgene, not only in terms of targeting efficiency of CAR cells but also of osteoblasts. However, taking into account the difference of targeted cells within a few days after birth, Adipoq-Cre transgene might start to target BM stromal cells slightly later than Lepr-Cre transgene. Additionally, a lineage tracing experiment proved that an Adipoq-Cre/ER 
transgene targets only $6 \%$ of Lepr $^{+}$stromal cell (20). We think that the difference in Cre expression might cause the difference in targeting efficiency between Adipoq-Cre and Adipoq-Cre/ER.

We also show that the Adipoq-Cre transgene targets a few mTECs, but not cTECs, in thymus (Supplementary Figure 4B). Expression of tissue-specific antigens (TSAs) in mTECs by transcription factors, AIRE and Fezf2, triggers deletion of autoreactive T cells and thereby induces central tolerance (45). AIRE deficiency results in autoimmune diseases restricted in specific organs. TSAs are expressed in only $1-5 \%$ of mTECs $(46,47)$. There are no age-dependent changes in expression levels of TSAs (48). Considereing the low frequency of Adipoq-Cre-targeted mTECs, it is possible that adiponectin expressed by Adipoq-Cre-targeted mTECs is one of the TSAs.

In IL-7 ${ }^{\mathrm{f} / \mathrm{f}}$ Adipoq-Cre mice, the reduction of mature B cells in BM and peripheral tissues is smaller than that of B cell precursors in BM (Fig. 7, Supplementary Figure 9 and 10), possibly because mature $\mathrm{B}$ cells accumulate in periphery. $\mathrm{T}$ cells decrease in mesenteric adipose tissue (MAT) but not in thymus of Adipoq-Cre IL-7 cKO mice (Supplementary Figure 8 and 9), suggesting a MAT-specific mechanism. Immunostaining reveals that there are no $\mathrm{IL}_{-} 7^{+}$cells in MAT (Supplementary Figure $6 \mathrm{~B}$ ). Thus, $\mathrm{IL}-7^{+}$adipocytes, undetectable by IL-7-GFP, might be present in MAT and support tissue-resident T cells.

The adipose tissue contains various hematopoietic cells such as T, NKT, NK, Treg, and macrophages, and gains much attention as an immunological organ. Adipocytes secrete various cytokines including IL-6, and immunological aspects of adipocytes are closely related to obesity and chronic inflammation. To study immunological mechanisms in adipose tissue, the Adipoq-Cre mouse line has been frequently used as a adipocyte-specific Cre driver (49). However, our data suggest that the Adipoq-Cre transgene has broader specificity than previously thought. It has been reported that adipocyte IL-15 is important for maintenance of 
systemic NK cells by using IL-15/f/f Adipoq-Cre mice (50). Because IL-15 gene was probably deleted in mesenchymal stromal cells of BM, NK cell development might be impaired in the IL-15 $5^{\mathrm{f} / \mathrm{f}}$ Adipoq-Cre mice. Thus, the interpretation of the previous results in $\mathrm{IL}-15^{\mathrm{f} / \mathrm{f}}$ Adipoq-Cre mice might be complicated.

Although in vitro studies suggest that adiponectin plays some roles in the immune system, it is still unclear whether adiponectin is indispensable for hematopoiesis in vivo. Adiponectin receptors, AdipoR1 and AdipoR2, are expressed on murine HSCs (14) and on human lymphocytes and monocytes (51). Systemic adiponectin knockout mice show larger number of major histocompatibility complex class $\mathrm{II}^{+}\left(\mathrm{MHC}-\mathrm{II}^{+}\right)$macrophages in $\mathrm{BM}(16)$. Besides, hematopoietic recovery was delayed in adiponectin knockout mice after BM ablation (52). These in vivo analyses suggest that adiponectin might play some roles in BM. It is of note that the expression level of adiponectin transcripts in PDGFR $\beta^{+} \mathrm{VCAM}-1^{+}$stromal cells of $\mathrm{BM}$ is higher than in adipocytes of adipose tissue and caudal vertebrae (Fig. 1). It is controversial whether BM adipocytes express as high levels of adiponectin as adipocytes in the adipose tissue. A previous study reported that BM adipocytes serve as a major source of circulating adiponectin (33). On the other hand, another study reported that BM adipocytes express lower levels of adiponectin than adipocytes in adipose tissue (53), which is consistent with our results. Our data raise the possibility that $\mathrm{BM}$ PDGFR $\beta^{+} \mathrm{VCAM}-1^{+}$stromal cells, many of which are overlapped with CAR cells, contribute to plasma adiponectin as well as adipocytes in adipose tissue. Considering importance of CAR cells in hematopoiesis, adiponectin produced by PDGFR $\beta^{+}$VCAM- $1^{+}$stromal cells might play an important role in BM

In conclusion, our study demonstrates that PDGFR $\beta^{+} \mathrm{VCAM}-1^{+}$stromal cells express adiponectin and are targeted by the Adipoq-Cre transgene, suggesting broader specificity of the Adipoq-Cre transgene than previously recognized. It is expected that future studies will elucidate the functions of adiponectin in BM hematopoiesis. 


\section{Funding}

This work was supported by JSPS KAKENHI Grant Numbers 16K15288, 16H05172, and 15H01153 (K.I.), 26460572 (S.T.), and 16K08835 (T.H.); and by the Joint Usage/Research Center program of Institute for Frontier Life and Medical Sciences Kyoto University.

\section{Acknowledgements}

We thank members of the Ikuta laboratory for discussion. 


\section{References}

1 Cordeiro Gomes, A., Hara, T., Lim, V. Y., et al. 2016. Hematopoietic stem cell niches produce lineage-instructive signals to control multipotent progenitor differentiation. Immunity 45:1219.

2 Ding, L. and Morrison, S. J. 2013. Haematopoietic stem cells and early lymphoid progenitors occupy distinct bone marrow niches. Nature 495:231.

3 Greenbaum, A., Hsu, Y. M., Day, R. B., et al. 2013. CXCL12 in early mesenchymal progenitors is required for haematopoietic stem-cell maintenance. Nature 495:227.

4 Omatsu, Y., Sugiyama, T., Kohara, H., et al. 2010. The essential functions of adipo-osteogenic progenitors as the hematopoietic stem and progenitor cell niche. Immunity 33:387.

5 Asada, N., Kunisaki, Y., Pierce, H., et al. 2017. Differential cytokine contributions of perivascular haematopoietic stem cell niches. Nat. Cell Biol. 19:214.

6 Morikawa, S., Mabuchi, Y., Kubota, Y., et al. 2009. Prospective identification, isolation, and systemic transplantation of multipotent mesenchymal stem cells in murine bone marrow. J. Exp. Med. 206:2483.

7 Kunisaki, Y., Bruns, I., Scheiermann, C., et al. 2013. Arteriolar niches maintain haematopoietic stem cell quiescence. Nature 502:637.

8 Mendez-Ferrer, S., Michurina, T. V., Ferraro, F., et al. 2010. Mesenchymal and haematopoietic stem cells form a unique bone marrow niche. Nature 466:829.

9 Bianco, P., Robey, P. G. and Simmons, P. J. 2008. Mesenchymal stem cells: revisiting history, concepts, and assays. Cell Stem Cell 2:313.

10 Fang, H. and Judd, R. L. 2018. Adiponectin regulation and function. Compr. Physiol. $8: 1031$. 
11 Fruebis, J., Tsao, T. S., Javorschi, S., et al. 2001. Proteolytic cleavage product of 30-kDa adipocyte complement-related protein increases fatty acid oxidation in muscle and causes weight loss in mice. Proc. Natl. Acad. Sci. USA. 98:2005.

12 Yamauchi, T., Kamon, J., Minokoshi, Y., et al. 2002. Adiponectin stimulates glucose utilization and fatty-acid oxidation by activating AMP-activated protein kinase. Nat. Med. 8:1288.

13 Yamauchi, T., Kamon, J., Waki, H., et al. 2001. The fat-derived hormone adiponectin reverses insulin resistance associated with both lipoatrophy and obesity. Nat. Med. $7: 941$

14 DiMascio, L., Voermans, C., Uqoezwa, M., et al. 2007. Identification of adiponectin as a novel hemopoietic stem cell growth factor. J. Immunol. 178:3511.

15 Kim, K. Y., Kim, J. K., Han, S. H., et al. 2006. Adiponectin is a negative regulator of NK cell cytotoxicity. J. Immunol. 176:5958.

16 Masamoto, Y., Arai, S., Sato, T., et al. 2016. Adiponectin enhances antibacterial activity of hematopoietic cells by suppressing bone marrow inflammation. Immunity 44:1422.

17 Yokota, T., Meka, C. S., Kouro, T., et al. 2003. Adiponectin, a fat cell product, influences the earliest lymphocyte precursors in bone marrow cultures by activation of the cyclooxygenase-prostaglandin pathway in stromal cells. J. Immunol. 171:5091.

18 Yokota, T., Oritani, K., Takahashi, I., et al. 2000. Adiponectin, a new member of the family of soluble defense collagens, negatively regulates the growth of myelomonocytic progenitors and the functions of macrophages. Blood 96:1723.

19 Berner, H. S., Lyngstadaas, S. P., Spahr, A., et al. 2004. Adiponectin and its receptors are expressed in bone-forming cells. Bone 35:842.

20 Zhou, B. O., Yu, H., Yue, R., et al. 2017. Bone marrow adipocytes promote the 
regeneration of stem cells and haematopoiesis by secreting SCF. Nat. Cell. Biol. 19:891.

21 Eguchi, J., Wang, X., Yu, S., et al. 2011. Transcriptional control of adipose lipid handling by IRF4. Cell Metab. 13:249.

22 Lee, K. Y., Russell, S. J., Ussar, S., et al. 2013. Lessons on conditional gene targeting in mouse adipose tissue. Diabetes 62:864.

23 Mullican, S. E., Tomaru, T., Gaddis, C. A., Peed, L. C., Sundaram, A. and Lazar, M. A. 2013. A novel adipose-specific gene deletion model demonstrates potential pitfalls of existing methods. Mol. Endocrinol. 27:127.

24 Shan, T., Zhang, P., Jiang, Q., Xiong, Y., Wang, Y. and Kuang, S. 2016. Adipocyte-specific deletion of mTOR inhibits adipose tissue development and causes insulin resistance in mice. Diabetologia 59:1995.

25 Tang, Y., Wallace, M., Sanchez-Gurmaches, J., et al. 2016. Adipose tissue mTORC2 regulates ChREBP-driven de novo lipogenesis and hepatic glucose metabolism. Nat. Commun. 7:11365.

26 Berry, R. and Rodeheffer, M. S. 2013. Characterization of the adipocyte cellular lineage in vivo. Nat. Cell Biol. 15:302.

27 Bi, P., Shan, T., Liu, W., et al. 2014. Inhibition of Notch signaling promotes browning of white adipose tissue and ameliorates obesity. Nat. Med. 20:911.

28 Ambrosi, T. H., Scialdone, A., Graja, A., et al. 2017. Adipocyte accumulation in the bone marrow during obesity and aging impairs stem cell-based hematopoietic and bone regeneration. Cell Stem Cell 20:771.

29 Srinivas, S., Watanabe, T., Lin, C. S., et al. 2001. Cre reporter strains produced by targeted insertion of EYFP and ECFP into the ROSA26 locus. BMC Dev. Biol. 1:4.

30 Ara, T., Tokoyoda, K., Sugiyama, T., Egawa, T., Kawabata, K. and Nagasawa, T. 2003. 
Long-term hematopoietic stem cells require stromal cell-derived factor-1 for colonizing bone marrow during ontogeny. Immunity 19:257.

31 Hara, T., Shitara, S., Imai, K., et al. 2012. Identification of IL-7-producing cells in primary and secondary lymphoid organs using IL-7-GFP knock-in mice. $J$ Immunol 189:1577.

32 Kawamoto, T. and Shimizu, M. 2000. A method for preparing 2- to 50-micron-thick fresh-frozen sections of large samples and undecalcified hard tissues. Histochem. Cell Biol. 113:331.

33 Cawthorn, W. P., Scheller, E. L., Learman, B. S., et al. 2014. Bone marrow adipose tissue is an endocrine organ that contributes to increased circulating adiponectin during caloric restriction. Cell Metab. 20:368.

34 Sheridan, J. M., Keown, A., Policheni, A., et al. 2017. Thymospheres are formed by mesenchymal cells with the potential to generate adipocytes, but not epithelial cells. Cell Rep. 21:934.

35 Yang, H., Youm, Y. H. and Dixit, V. D. 2009. Inhibition of thymic adipogenesis by caloric restriction is coupled with reduction in age-related thymic involution. $J$. Immunol. 183:3040.

36 Yang, H., Youm, Y. H., Sun, Y., et al. 2009. Axin expression in thymic stromal cells contributes to an age-related increase in thymic adiposity and is associated with reduced thymopoiesis independently of ghrelin signaling. J. Leukoc. Biol. 85:928.

37 Cepeda, S. and Griffith, A. V. 2018. Thymic stromal cells: roles in atrophy and age-associated dysfunction of the thymus. Exp. Gerontol. 105:113.

38 Youm, Y. H., Yang, H., Sun, Y., et al. 2009. Deficient ghrelin receptor-mediated signaling compromises thymic stromal cell microenvironment by accelerating thymic adiposity. J. Biol. Chem. 284:7068. 
39 Chaudhry, M. S., Velardi, E., Dudakov, J. A. and van den Brink, M. R. 2016. Thymus: the next (re)generation. Immunol. Rev. 271:56.

40 den Haan, J. M., Mebius, R. E. and Kraal, G. 2012. Stromal cells of the mouse spleen. Front. Immunol. 3:201.

41 Malhotra, D., Fletcher, A. L., Astarita, J., et al. 2012. Transcriptional profiling of stroma from inflamed and resting lymph nodes defines immunological hallmarks. Nat. Immunol. 13:499.

42 Shitara, S., Hara, T., Liang, B., et al. 2013. IL-7 produced by thymic epithelial cells plays a major role in the development of thymocytes and $\mathrm{TCR} \gamma \delta^{+}$intraepithelial lymphocytes. J. Immunol. 190:6173.

43 Zhou, B. O., Yue, R., Murphy, M. M., Peyer, J. G. and Morrison, S. J. 2014. Leptin-receptor-expressing mesenchymal stromal cells represent the main source of bone formed by adult bone marrow. Cell Stem Cell 15:154.

44 Chen, J., Shi, Y., Regan, J., Karuppaiah, K., Ornitz, D. M. and Long, F. 2014. Osx-Cre targets multiple cell types besides osteoblast lineage in postnatal mice. PLoS One 9:e85161.

45 Takaba, H., Morishita, Y., Tomofuji, Y., et al. 2015. Fezf2 orchestrates a thymic program of self-antigen expression for immune tolerance. Cell 163:975.

46 Anderson, A. C. and Kuchroo, V. K. 2003. Expression of self-antigen in the thymus: a little goes a long way. J. Exp. Med. 198:1627.

47 Gallegos, A. M. and Bevan, M. J. 2004. Central tolerance to tissue-specific antigens mediated by direct and indirect antigen presentation. J. Exp. Med. 200:1039.

48 Derbinski, J., Schulte, A., Kyewski, B. and Klein, L. 2001. Promiscuous gene expression in medullary thymic epithelial cells mirrors the peripheral self. Nat. Immunol. 2:1032. 
49 Liu, J., Xu, Z., Wu, W., Wang, Y. and Shan, T. 2017. Cre recombinase strains used for the study of adipose tissues and adipocyte progenitors. J. Cell. Physiol. 232:2698.

50 Liou, Y. H., Wang, S. W., Chang, C. L., et al. 2014. Adipocyte IL-15 regulates local and systemic NK cell development. J. Immunol. 193:1747.

51 Keustermans, G., van der Heijden, L. B., Boer, B., et al. 2017. Differential adipokine receptor expression on circulating leukocyte subsets in lean and obese children. PLoS One 12:e187068.

52 Masamoto, Y., Arai, S., Sato, T., et al. 2017. Adiponectin enhances quiescence exit of murine hematopoietic stem cells and hematopoietic recovery through mTORC1 potentiation. Stem Cells 35:1835.

53 Liu, L. F., Shen, W. J., Ueno, M., Patel, S. and Kraemer, F. B. 2011. Characterization of age-related gene expression profiling in bone marrow and epididymal adipocytes. BMC Genomics 12:212. 


\section{Figure Legends}

Figure 1. PDGFR $\beta^{+} \mathrm{VCAM}-1^{+}$stromal cells in bone marrow express adiponectin.

(A) Gating strategy for Ter $119^{-} \mathrm{CD} 45^{-} \mathrm{CD} 31^{-} \mathrm{Sca}-1^{-} \mathrm{PDGFR} \beta^{+} \mathrm{VCAM}-1^{+}$stromal cells, blood vascular endothelial cells (BECs, Ter119- $\left.\mathrm{CD} 45^{-} \mathrm{CD} 31^{+} \mathrm{Sca}-1^{+}\right)$, and other stromal cells in bone marrow (BM). (B) Gross anatomy of the centrums of thoracic vertebrae (TV), sacral vertebrae (SV), and caudal vertebrae (CV) at 8 weeks old. (C) Plin1 (perilipin) transcripts in the whole TV, SV, and $\mathrm{CV}$ at 8 weeks old were measured by real-time RT-PCR and normalized to those of HPRT. The transcript levels in the TV were normalized to 1. Data are means \pm SEM from 3 mice in one experiment. ${ }^{* *} p<0.01$. (D) Adipoq (adiponectin) and Plin1 (perilipin) transcripts in adipocytes of perigonadal adipose tissue (PAT), adipocytes of caudal vertebrae $(\mathrm{CV}), \mathrm{PDGFR} \beta^{+} \mathrm{VCAM}-1^{+}$stromal cells, BECs, other stromal cells, and hematopoietic cells sorted from BM at 8 weeks old were measured by real-time RT-PCR and normalized to those of HPRT. The transcript levels in PAT adipocytes were normalized to 1. Data are means \pm SEM from 3-4 mice in 2 independent experiments. ${ }^{* * *} p<0.001$. (E) Flow cytometric analysis of Cre expression in Ter $119^{-} \mathrm{CD} 45^{-} \mathrm{CD} 31^{-} \mathrm{Sca}-1^{-} \mathrm{PDGFR} \beta^{+} \mathrm{VCAM}-1^{+}$ cells (solid line with untinted area), other stromal cells (dotted line with tinted area), and hematopoietic cells (solid line with tinted area) in Adipoq-Cre BM. (F) Percentages of $\mathrm{Cre}^{+}$ cells in Ter $119^{-} \mathrm{CD} 45^{-} \mathrm{CD} 31^{-} \mathrm{Sca}-1^{-} \mathrm{PDGFR} \beta^{+} \mathrm{VCAM}-1^{+}$cells in BM from Adipoq-Cre mice at 8 weeks old $(n=6)$. Data are means \pm SEM.

Figure 2. Adipoq-Cre transgene targets a majority of PDGFR $\beta^{+} \mathrm{VCAM}-1^{+}$stromal cells in BM.

(A) Flow cytometric analysis of Tomato expression in Ter119- CD45-CD31-Sca-1 ${ }^{-}$PDGFR $\beta^{+} \mathrm{VCAM}^{-} 1^{+}$cells, blood vascular endothelial cells 
(BECs, Ter $119^{-} \mathrm{CD} 45^{-} \mathrm{CD} 31^{+} \mathrm{Sca}-1^{+}$), Ter $119^{-} \mathrm{CD} 45^{-} \mathrm{CD} 31^{-} \mathrm{Sca}-1^{+}$cells, and other stromal cells in the inner compartment of bone marrow (I-BM) from Adipoq-Cre ${ }^{+}$; R26 $6^{\text {tdTomato/+ }}$ mice at 8 weeks old. (B) Flow cytometric analysis of Tomato expression in osteoblasts $\left(\right.$ Ter119- CD45 ${ }^{-} \mathrm{CD} 31^{-} \mathrm{Sca}-1^{-}{ }^{-}$DGFR $\left.\beta^{\text {int }} \mathrm{ALP}^{+}\right)$, BECs, and Ter119 ${ }^{-} \mathrm{CD} 45^{-} \mathrm{CD} 31^{-} \mathrm{Sca}-1^{+}$cells associated with the endosteal surface of bone marrow (E-BM) in Adipoq-Cre ${ }^{+}$; $26^{\text {tdTomato/ }}$ mice at 8 weeks old. (C) Percentages of Tomato ${ }^{+}$cells in the indicated cells shown in A and B $(n=8)$. Data are means \pm SEM. (D) Flow cytometric analysis of Cre and Tomato expression in Ter $119^{-} \mathrm{CD} 45^{-} \mathrm{CD} 31^{-} \mathrm{Sca}-1^{-} \mathrm{PDGFR} \beta^{+} \mathrm{VCAM}-1^{+}$cells and other stromal cells in the inner compartment of bone marrow (I-BM) from Adipoq-Cre ${ }^{+} ; \mathrm{R}^{2} 6^{\text {tdTomato/+ }}$ mice at 8 weeks old.

Figure 3. Adipoq-Cre transgene targets mesenchymal stromal cells in BM.

(A) Tomato expression was detected in many of $\mathrm{S} 100^{+}$stromal cells in Adipoq-Cre ${ }^{+}$; R26 $6^{\text {tdTomato/+ }}$ I-BM at 8 weeks old. (B) Tomato expression was rarely detected in ALP $^{+}$ osteoblasts or Sca- $1^{+}$blood endothelial cells (BECs) in Adipoq-Cre ${ }^{+} ; \mathrm{R}^{2} 6^{\text {tdTomato/ }}$ E-BM at 8 weeks old. The dotted line represents endosteum. (C) Tomato expression was detected in perilipin $^{+}$adipocytes (arrowhead) in Adipoq-Cre ${ }^{+} ; \mathrm{R}_{2} 6^{\text {tdTomato/+ }} \mathrm{BM}$ and mesenteric adipose tissue at 8 weeks old. Scale bar, $50 \mu \mathrm{m}$.

Figure 4. A majority of the bone marrow stromal cells targeted by Adipoq-Cre transgene are CAR cells.

(A) Flow cytometric analysis of Tomato expression in $\mathrm{GFP}^{-}$and $\mathrm{GFP}^{+}$stromal cells in $\mathrm{BM}$ of Adipoq-Cre ${ }^{+}$; R26 $6^{\text {tdTomato/+}}$; Cxcl12 ${ }^{\mathrm{GFP} /+}$ mice at 8 weeks old. (B) Percentage of Tomato $^{+}$cells in $\mathrm{GFP}^{+}$stromal cells shown in A $(n=5)$. Data are means \pm SEM. (C) Flow cytometric analysis of GFP expression in Tomato $^{-}$and Tomato $^{+}$stromal cells in Adipoq-Cre ${ }^{+}$; $\mathrm{R}^{\text {tdTomato/+}}$; $\mathrm{Cxcl12} 2^{\mathrm{GFP} /+} \mathrm{BM}$ at 8 weeks old. (D) Percentage of $\mathrm{GFP}^{+}$cells in Tomato ${ }^{+}$ 
stromal cells shown in $\mathrm{C}(n=5)$. Data are means \pm SEM. (E) Immunohistochemistry of BM of Adipoq-Cre ${ }^{+}$; R26 $6^{\text {tdTomato/+}}$; Cxcl12 $2^{\mathrm{GFP} /+}$ mice at 8 weeks old. Scale bar, $100 \mu \mathrm{m}$.

Figure 5. Adipoq-Cre transgene targets $\mathrm{PDGFR} \beta^{+} \mathrm{VCAM}-1^{+}$stromal cells and osteoblasts in an age-dependent manner.

(A) and (B) Flow cytometric analysis of Tomato expression in Ter119 ${ }^{-} \mathrm{CD} 45^{-} \mathrm{CD} 31^{-} \mathrm{Sca}-1^{-} \mathrm{PDGFR} \beta^{+} \mathrm{VCAM}^{+}{ }^{+}$stromal cells and osteoblasts $\left(\right.$ Ter1 $\left.19^{-} \mathrm{CD}^{-} 5^{-} \mathrm{CD} 31^{-} \mathrm{Sca}-1^{-} \mathrm{PDGFR}^{\text {int }} \mathrm{ALP}^{+}\right)$in $\mathrm{BM}$ of Adipoq-Cre ${ }^{+}$; $\mathrm{R}^{\text {tdTomato/+ }}$ mice at 4 (A) and 24 (B) weeks old. (C) Percentages of Tomato ${ }^{+}$cells in indicated cell populations of Adipoq-Cre ${ }^{+}$; $26^{\text {tdTomato/+ }}$ BM at different ages $(n=6,8$, and 5 for 4-, 8-, and 24-week-old mice, respectively). Data are means \pm SEM. ${ }^{*} p<0.05, * * * p<0.001, n . s$. , not significant. (D) Tomato expression in $\mathrm{ALP}^{+}$osteoblasts in Adipoq-Cre ${ }^{+} ; \mathrm{R}_{2} 6^{\text {tdTomato/+ }}$ mice at 8 and 24 weeks old. White arrows show Tomato ${ }^{+}$osteoblasts. Scale bar, $50 \mu \mathrm{m}$. (E) Tomato expression in BM from Adipoq-Cre ${ }^{+}$: R26 ${ }^{\text {tdTomato/+ }}$ mice at postnatal day 0 (P0), day 1 (P1), and day 7 (P7). Scale bar, $50 \mu \mathrm{m}$.

Figure 6. Many of IL- $7^{+}$bone marrow stromal cells are targeted by Adipoq-Cre transgene.

(A) IL-7-GFP and Tomato expression in Ter $119^{-} \mathrm{CD} 45^{-} \mathrm{CD} 31^{-} \mathrm{Sca}-1^{-} \mathrm{PDGFR} \beta^{+} \mathrm{VCAM}-1^{+}$ stromal cells in $\mathrm{BM}$ of Adipoq-Cre ${ }^{+}$: R26 $6^{\text {tdTomato/+}}$; IL $7^{\mathrm{GFP} /+}$ mice at 8 weeks old (left panel) and percentages of indicated cells (right graph) $(n=6)$. Data are means \pm SEM. Immunohistochemistry of BM of Adipoq-Cre ${ }^{+}$: R2 $6^{\text {tdTomato/+}} ;$ IL $7^{\mathrm{GFP} /+}$ mice at 8 weeks old.

Figure 7. B cell development in BM is severely impaired in IL- $7^{\mathrm{f} / \mathrm{f}}$ Adipoq-Cre mice. 
(A) Flow cytometric analysis of B cell development in BM of IL-7 $7^{\mathrm{f} / \mathrm{f}}$ and IL-7 ${ }^{\mathrm{f} / \mathrm{f}}$ Adipoq-Cre mice at 8 weeks old. (B) Percentages and absolute numbers of each cell population $(n=6)$. Data are means \pm SEM. ${ }^{*} p<0.05, * * p<0.01, * * * p<0.001$ 


\section{Legends to Supplementary Figures}

Supplementary Figure 1. PDGFR $\beta^{+} \mathrm{VCAM}-1^{+}$stromal cells in bone marrow express adiponectin even at 4 weeks old.

(A) Adipoq (adiponectin) and transcripts in adipocytes of perigonadal adipose tissue (PAT), PDGFR $\beta^{+}$VCAM $-1^{+}$stromal cells, BECs, other stromal cells, and hematopoietic cells sorted from BM at 4 weeks old were measured by real-time RT-PCR and normalized to those of HPRT. The transcript levels in PAT adipocytes at 8 weeks old were normalized to 1. Data are means \pm SEM from 3 mice in one experiment. ${ }^{* *} p<0.001$. (B) Flow cytometric analysis of Cre expression in Ter $119^{-} \mathrm{CD} 45^{-} \mathrm{CD} 31^{-} \mathrm{Sca}-1^{-} \mathrm{PDGFR} \beta^{+} \mathrm{VCAM}-1^{+}$cells, BECs, other stromal cells, and hematopoietic cells in Adipoq-Cre BM at 4 weeks old. In the overlaid histogram, solid line with untinted area, long-dashed line with tinted area, dotted line with tinted area, and solid line with tinted area represents PDGFR $\beta^{+} \mathrm{VCAM}-1^{+}$cells, BECs, other stromal cells, and hematopoietic cells, respectively. (C) Percentages of $\mathrm{Cre}^{+}$cells in Ter119 ${ }^{-} \mathrm{CD} 45^{-} \mathrm{CD} 31^{-} \mathrm{Sca}-1^{-} \mathrm{PDGFR} \beta^{+} \mathrm{VCAM}^{+}{ }^{+}$cells in $\mathrm{BM}$ from Adipoq-Cre mice at 4 weeks old $(n=3)$. Data are means \pm SEM.

Supplementary Figure 2. Tomato expression in perilipin ${ }^{+}$adipocytes (arrowhead) of Adipoq-Cre ${ }^{+}$; $26^{\text {tdTomato/+ }}$ bone marrow with serial sections at 8 weeks old. Scale bar, $50 \mu \mathrm{m}$.

Supplementary Figure 3. YFP expression in Adipoq-Cre ${ }^{+}$, R26 $6^{\mathrm{YFP} /+}$ mice.

(A) Flow cytometric analysis of YFP expression in Ter119 ${ }^{-} \mathrm{CD} 45^{-} \mathrm{CD} 31^{-} \mathrm{Sca}-1^{-} \mathrm{PDGFR} \beta^{+} \mathrm{VCAM}^{+}{ }^{+}$stromal cells and osteoblasts $\left(\right.$ Ter1 $\left.19^{-} \mathrm{CD} 45^{-} \mathrm{CD} 31^{-} \mathrm{Sca}-1^{-} \mathrm{PDGFR}^{\text {int }} \mathrm{ALP}^{+}\right)$in bone marrow (BM) of Adipoq-Cre ${ }^{+}$; R26 $6^{\text {tdTomato/+ }}$ mice at 8 weeks old. (B) Percentages of $\mathrm{YFP}^{+}$cells in the indicated cell 
populations in BM shown in A $(n=4)$. Data are means \pm SEM. (C) YFP expression in Adipoq-Cre ${ }^{+}$: R26 $6^{\mathrm{YFP} /+} \mathrm{BM}$ at 8 weeks old. Scale bar, $50 \mu \mathrm{m}$.

Supplementary Figure 4. Tomato expression in Adipoq-Cre ${ }^{+}$, R2 $6^{\text {tdTomato/+ }}$ mice.

(A) Flow cytometric analysis of Tomato expression in thymic epithelial cells (TECs) and other stromal cells in Adipoq-Cre ${ }^{+}$; R26 tdomato/+ thymus at 8 weeks old. (B) Percentages of Tomato $^{+}$cells in the indicated cell populations in thymus at $8(n=5)$ and $24(n=5)$ weeks old. Data are means \pm SEM. $(\mathbf{C}, \mathbf{D}, \mathbf{E})$ Tomato expression in Adipoq-Cre ${ }^{+} ; \mathrm{R}^{26^{\text {tdTomato } /}}$ thymus (C), spleen (D), and mesenteric lymph nodes (mLNs) (E) at 8 weeks old. Scale bars are 100 $\mu \mathrm{m}(\mathrm{C}), 200 \mu \mathrm{m}(\mathrm{D})$, and $50 \mu \mathrm{m}(\mathrm{E})$.

Supplementary Figure 5. Tomato ${ }^{+}$cells expand dramatically within 1 week after birth in bone marrow of Adipoq-Cre ${ }^{+} ; \mathrm{R}^{\mathrm{tdTomato} /+}$ mice.

(A) Tomato expression in Adipoq-Cre ${ }^{+}$; $26^{\text {tdTomato/+ }}$ bone marrow at postnatal day 0. (B) Tomato expression in Adipoq-Cre ${ }^{+}$: $\mathrm{R}^{6^{\mathrm{tdTomato} /+}}$ bone marrow at postnatal day 0 (P0), postnatal day $1(\mathrm{P} 1)$, and postnatal day $2(\mathrm{P} 2)$. The dotted line represents endosteum. Scale bar, $200 \mu \mathrm{m}$.

Supplementary Figure 6. Adipocytes are IL-7-negative in bone marrow and adipose tissue of IL $7^{\mathrm{GFP} /+}$ mice.

(A, B) GFP and perilipin expression in $\mathrm{IL}^{\mathrm{GFP} /+}$ bone marrow (A) and mesenteric adipose tissue (B) at 8 weeks old. Scale bars are $100 \mu \mathrm{m}$ (A) and $50 \mu \mathrm{m}$ (B).

Supplementary Figure 7. NK cells increase in IL-7/f Adipoq-Cre bone marrow. 
(A) Flow cytometric analysis of NKT $\left(\mathrm{CD}^{+} \mathrm{NK} 1.1^{+}\right)$, invariant NKT (iNKT, $\mathrm{CD}^{+} \mathrm{NK} 1.1^{+} \mathrm{CD} 1 \mathrm{~d}$-tetramer $\left.{ }^{+}\right), \mathrm{NK}\left(\mathrm{CD} 3^{-} \mathrm{NK} 1.1^{+}\right)$, and $\mathrm{T}\left(\mathrm{CD}^{+} \mathrm{NK} 1.1^{-}\right)$cells in bone marrow of IL-7 $7^{\mathrm{f} / \mathrm{f}}$ and IL-7 ${ }^{\mathrm{f} / \mathrm{f}}$ Adipoq-Cre mice at 8 weeks old. (B) Percentages and absolute numbers of each cell population $(n=8)$. Data are means \pm SEM. $* p<0.05, * * p<0.01, * * * p$ $<0.001$.

Supplementary Figure 8. Thymocytes are unchanged in IL- $7^{\mathrm{f} / \mathrm{f}}$ Adipoq-Cre mice.

(A) Flow cytometric analysis of thymocyte subpopulations in IL-7 $7^{\mathrm{f} / \mathrm{f}}$ and IL-7 $7^{\mathrm{f} / \mathrm{f}}$ Adipoq-Cre mice at 8 weeks old. (B) Percentages and absolute numbers of each cell population $(n=6)$. Data are means \pm SEM.

Supplementary Figure 9. B and T cells are reduced in mesenteric but not in perigonadal adipose tissue of IL-7 $7^{\mathrm{f} / \mathrm{f}}$ Adipoq-Cre mice.

(A, B) Flow cytometric analysis of NKT, NK, B, and T cells in perigonadal adipose tissue (A) and mesenteric adipose tissue (B) from IL- $7^{\mathrm{f} / \mathrm{f}}$ and IL-7 ${ }^{\mathrm{f} / \mathrm{f}}$ Adipoq-Cre mice at 8 weeks old. (C, D) Percentages and absolute numbers of each cell population in perigonadal adipose tissue (C) $(n=6)$ and mesenteric adipose tissue (D) $(n=8)$. Data are means \pm SEM. ${ }^{*} p<0.05, * * p$ $<0.01, * * * p<0.001$

Supplementary Figure 10. B cells are significantly reduced in spleen and lymph nodes of IL-7 ${ }^{\mathrm{f} / \mathrm{f}}$ Adipoq-Cre mice.

(A, B) Flow cytometric analysis of NK, NKT, T, and B cells in spleen (A) and mesenteric lymph nodes (B) from IL-7 ${ }^{\mathrm{f} / \mathrm{f}}$ and IL- $7^{\mathrm{f} / \mathrm{f}}$ Adipoq-Cre mice at 8 weeks old. (C, D) Percentages and absolute numbers of each cell population in spleen (C) $(n=6-10)$ and mesenteric lymph nodes (D) $(n=6)$. Data are means \pm SEM. ${ }^{*} p<0.05,{ }^{* *} p<0.01, * * * p<0.001$. 

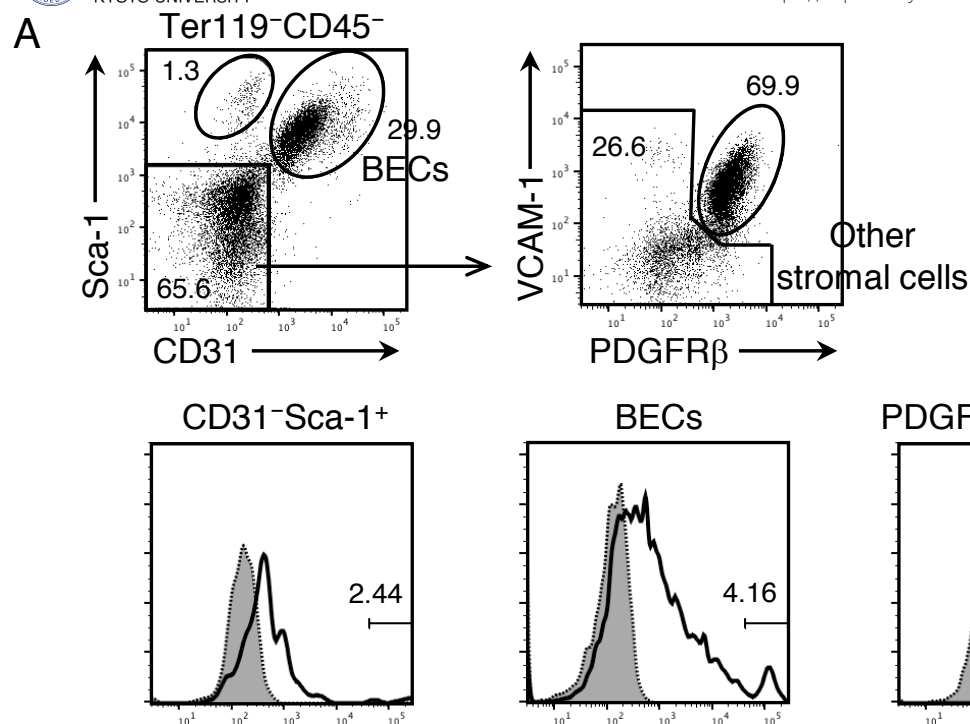

PDGFR $\beta^{+}$VCAM- 1

Other stromal cells

tdTomato
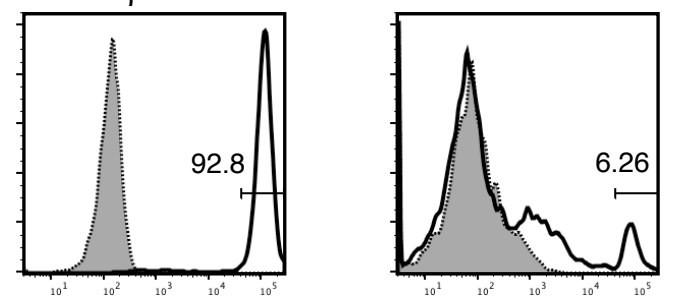

B
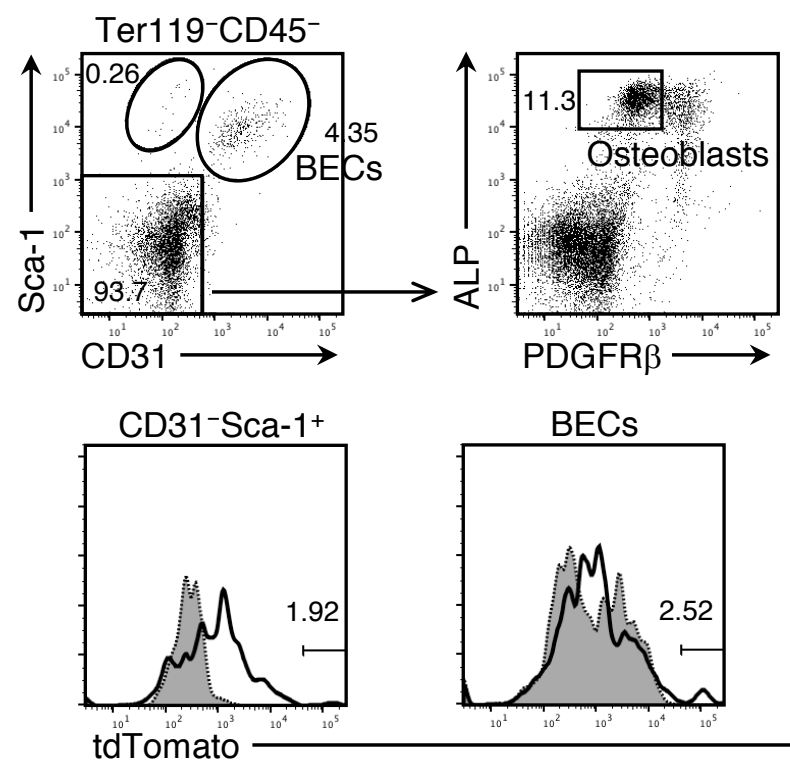

Osteoblasts

C

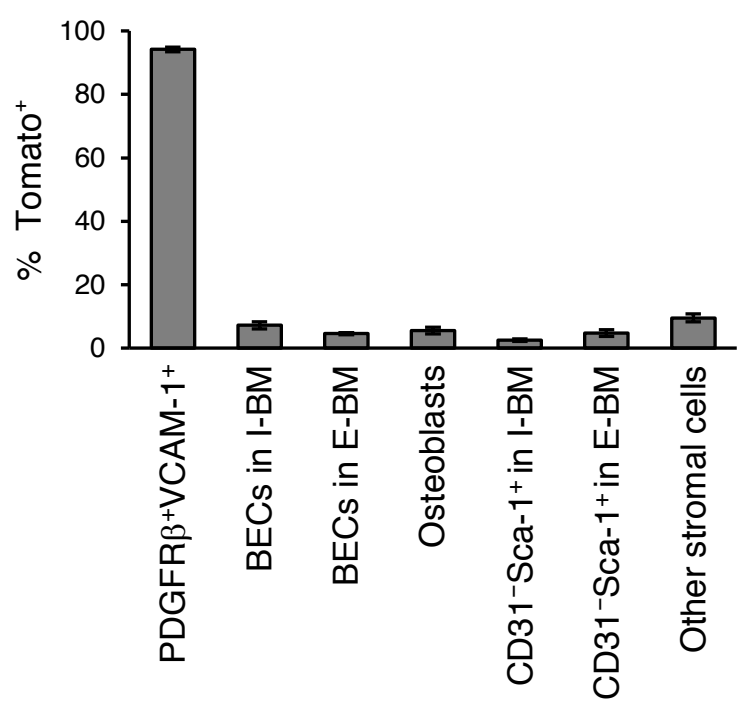

D PDGFR $\beta+$ VCAM-1+

Other stromal cells
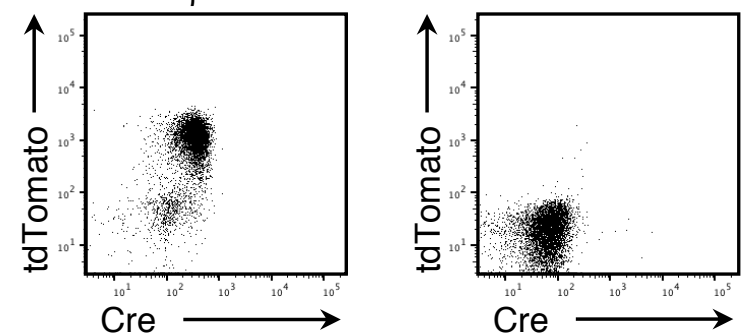
A Adipoq-Cre ${ }^{+} ;$R26 $^{\text {tdTomato }}$ BM
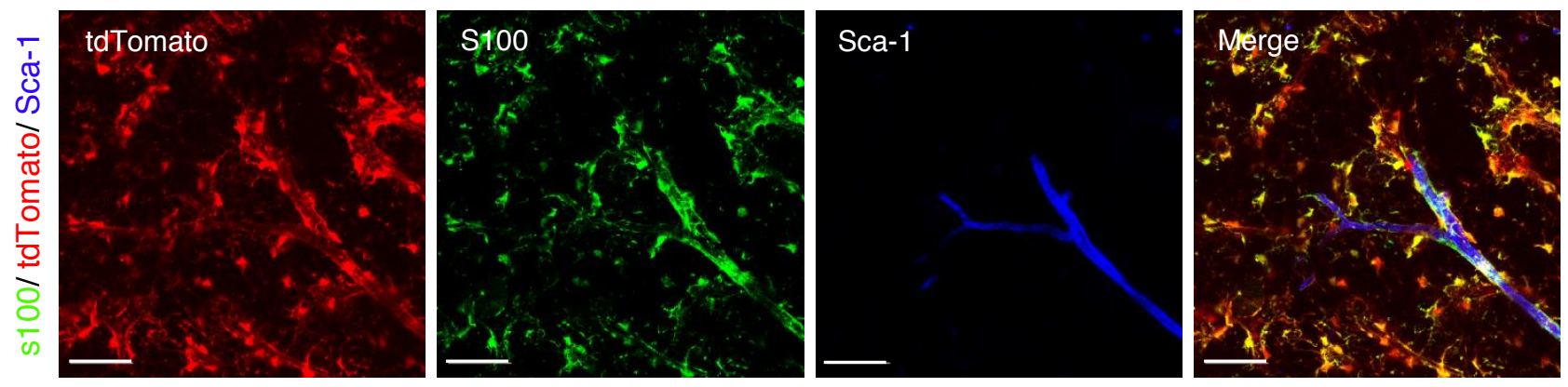

B Adipoq-Cre ${ }^{+} ;$R26 $^{\text {tdTomato }}$ BM
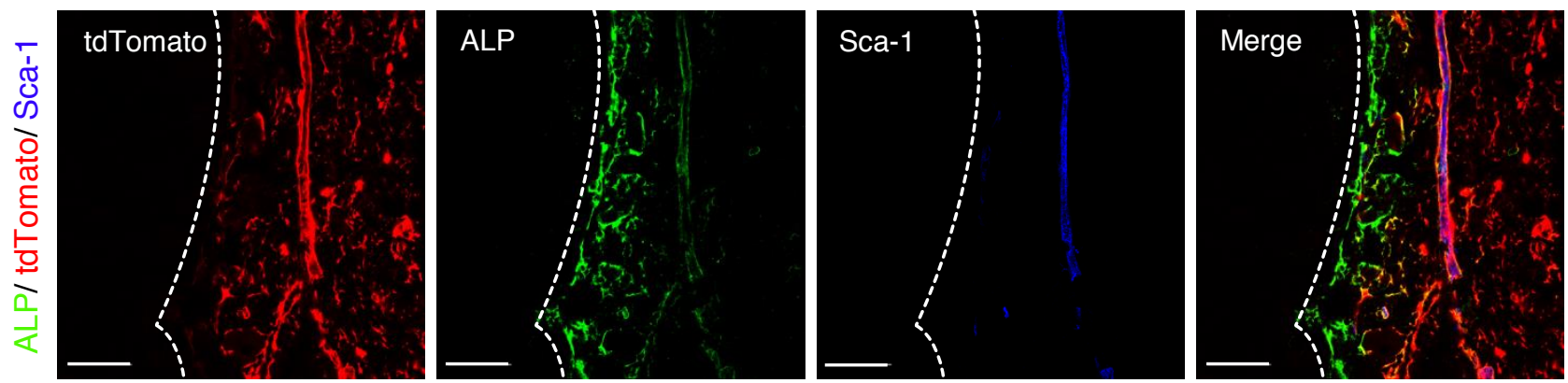

C

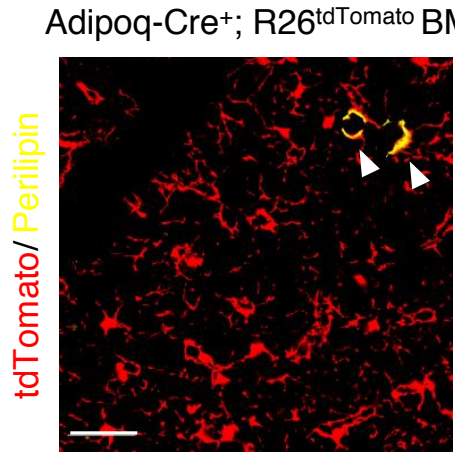

Adipoq-Cre+; R26 ${ }^{\text {tdTomato }}$ Mesentery

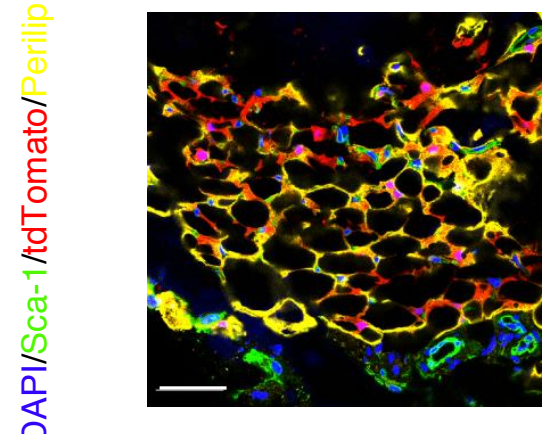


210 都大学

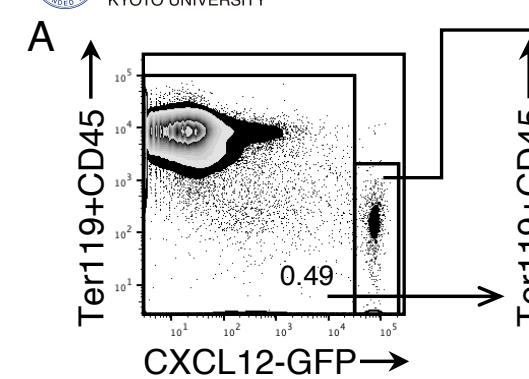

C
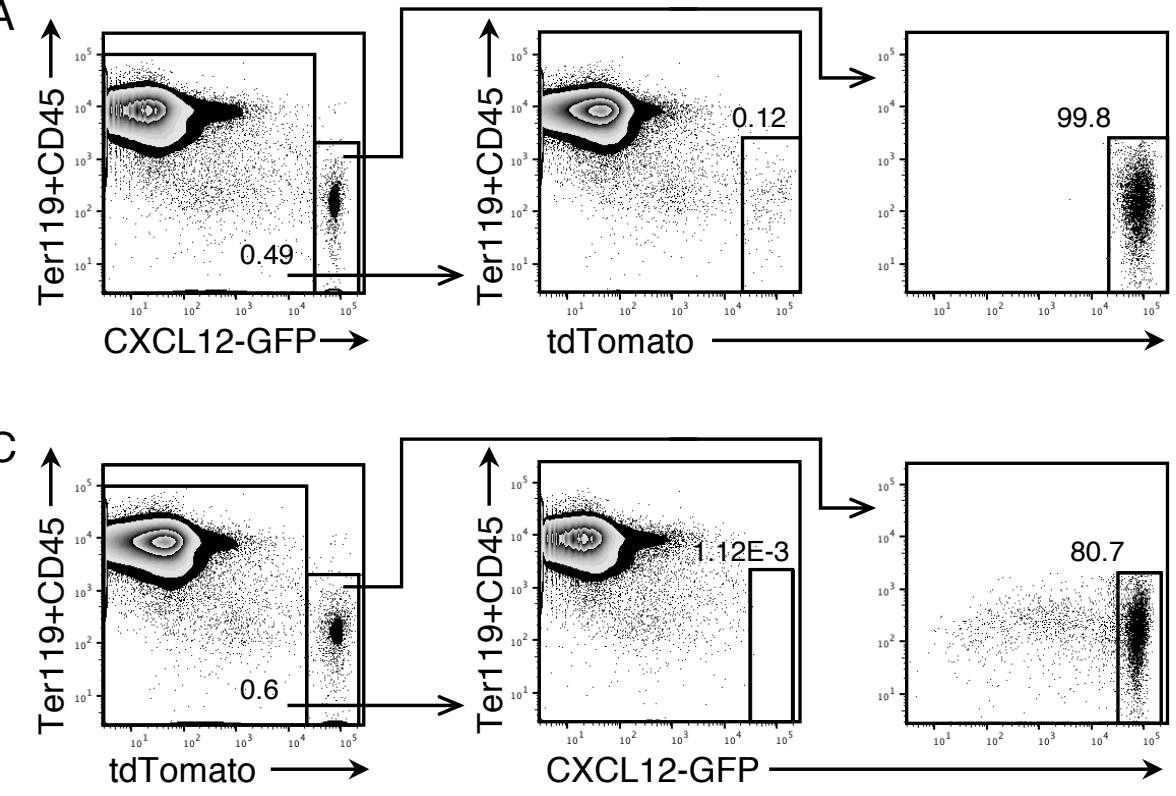

$E$

Adipoq-Cre+; R26 tdTomato; CXCL12 ${ }^{\mathrm{GFP} /+}$

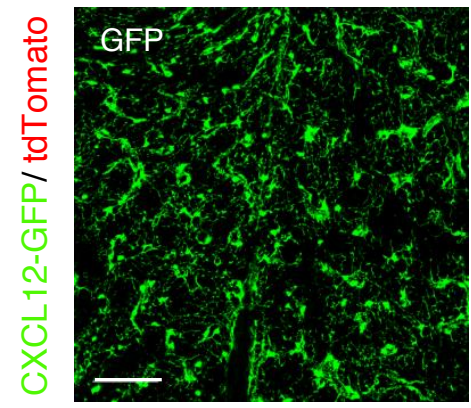

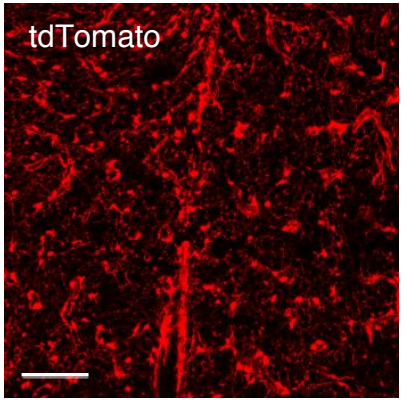

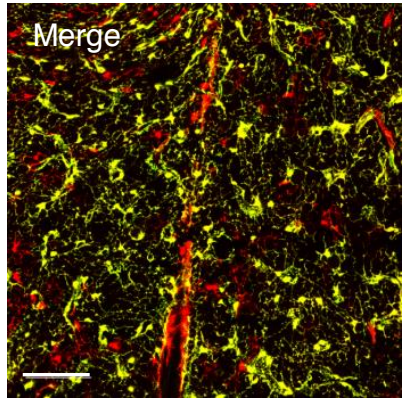

B

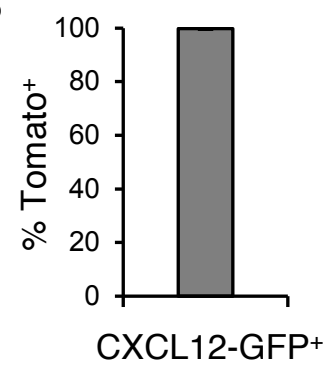

D

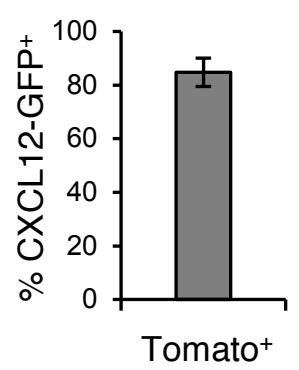




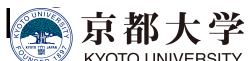

A Ter119-CD45-CD31-Sca-1-
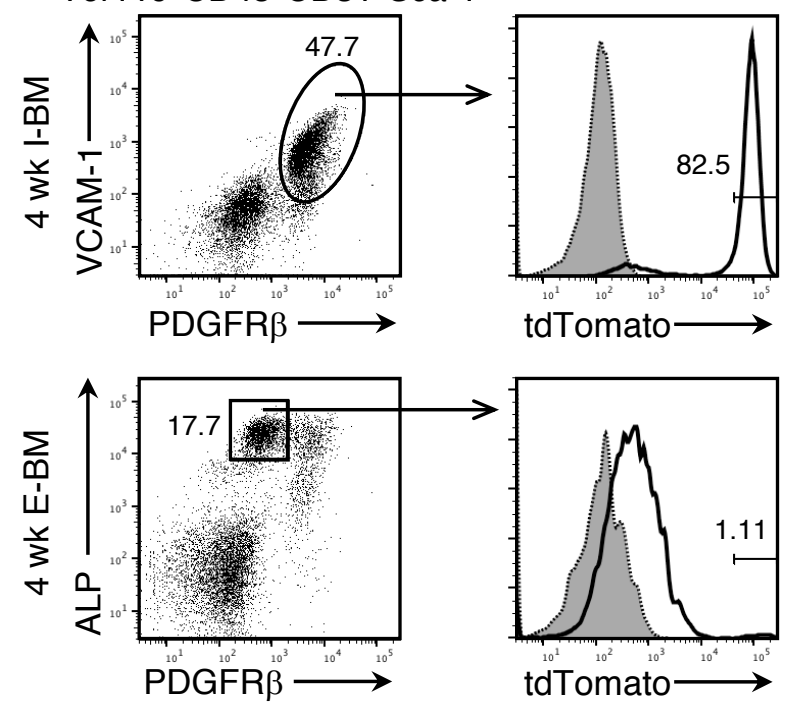

C

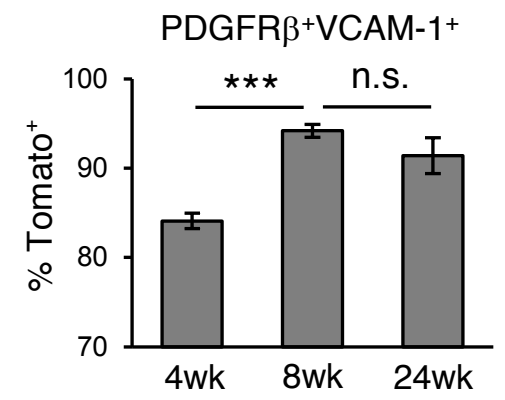

Osteoblasts

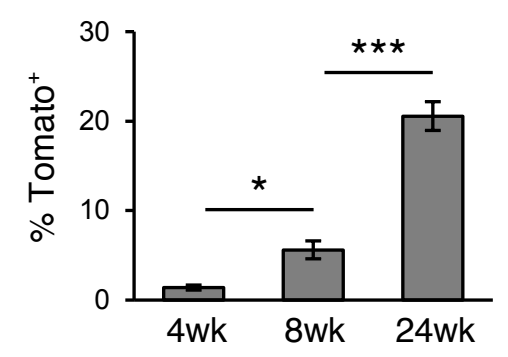

B Ter119-CD45-CD31-Sca-1-
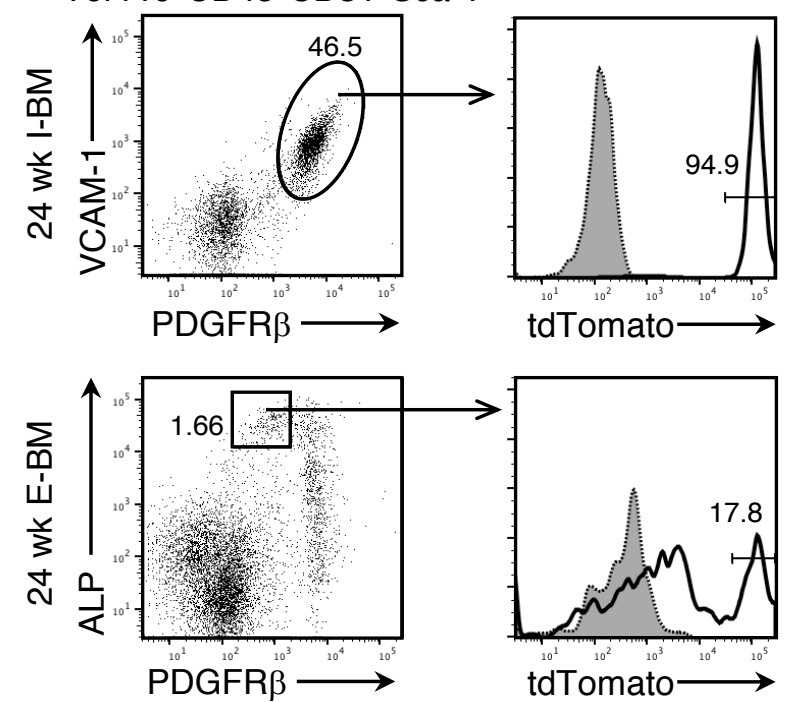

Adipoq-Cre+; R26 ${ }^{\text {tdTomato }}$ BM
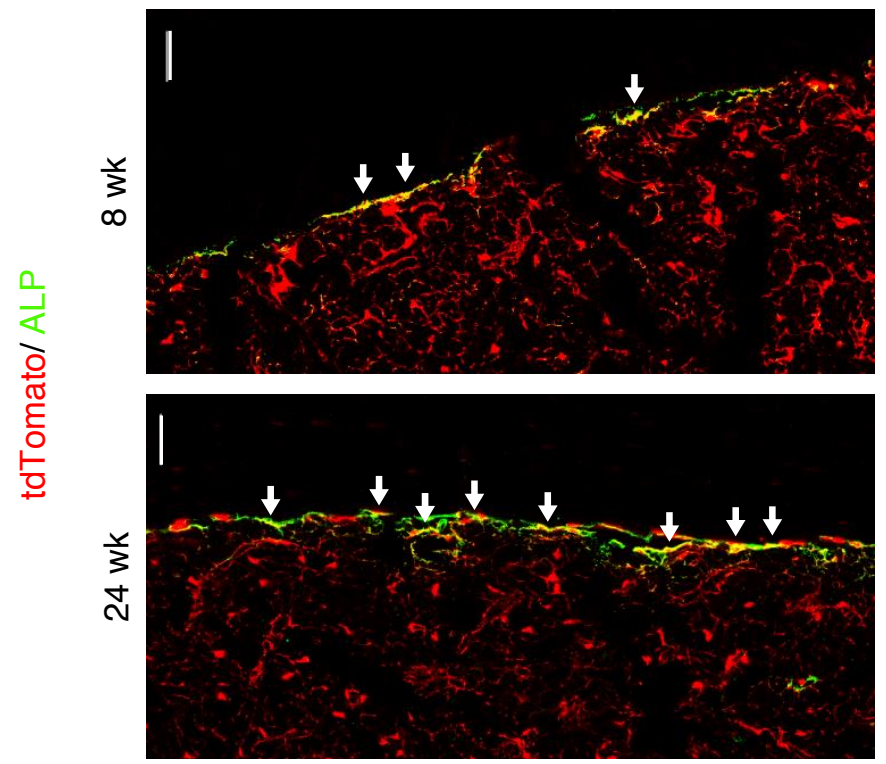

E Adipoq-Cre ${ }^{+} ;$R26 $^{\text {tdTomato }}$ BM

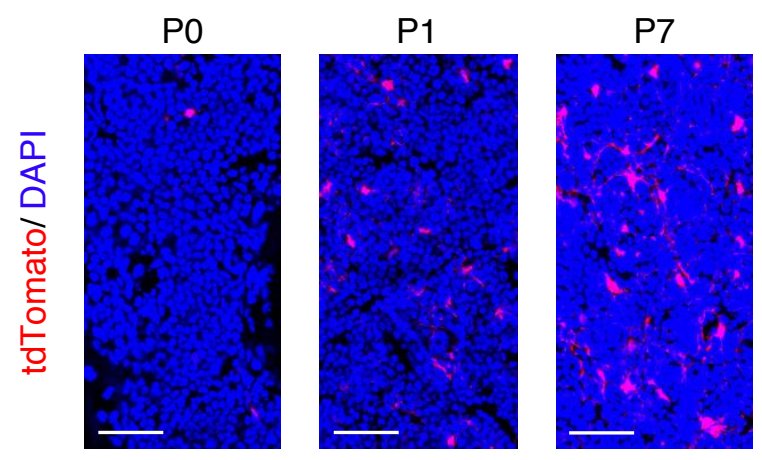


A

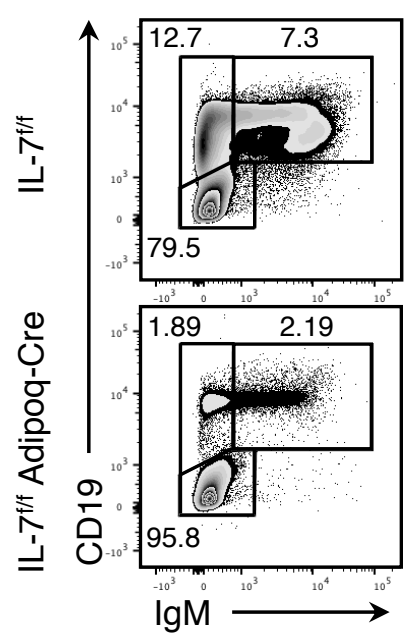

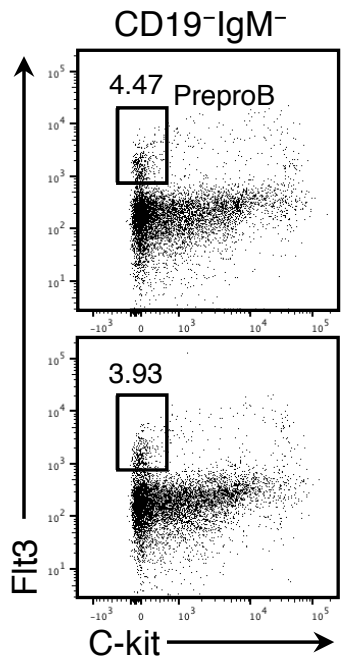
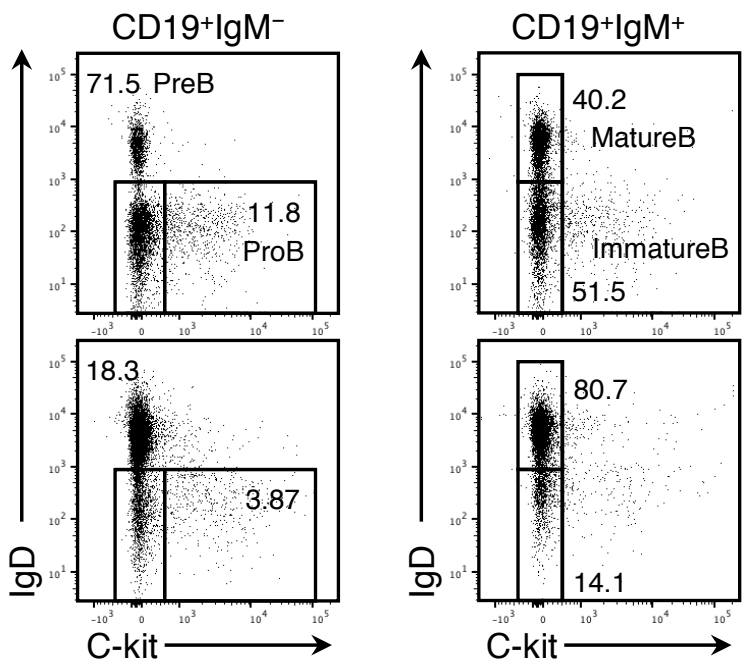

B

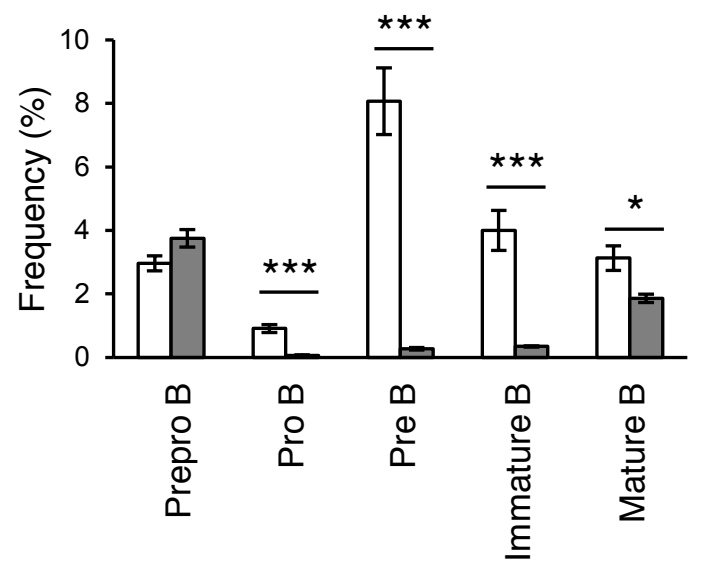

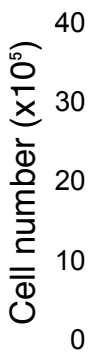

***

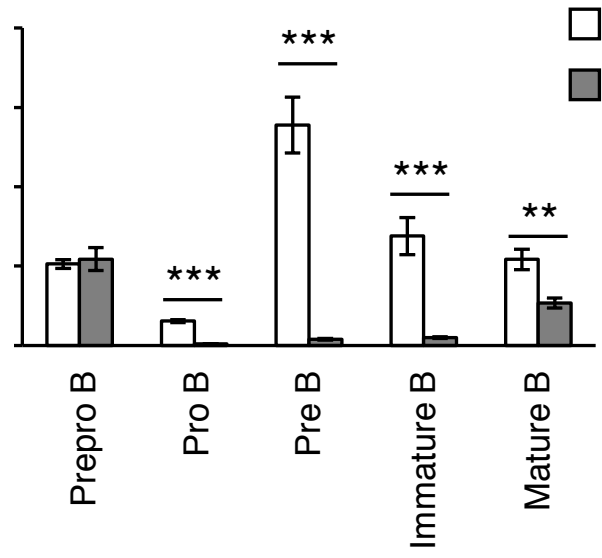

$\square \mathrm{IL}-7^{\mathrm{ft/}}$

$\square \mathrm{IL}-7^{\mathrm{ft/}}$ Adipoq-Cre 
A

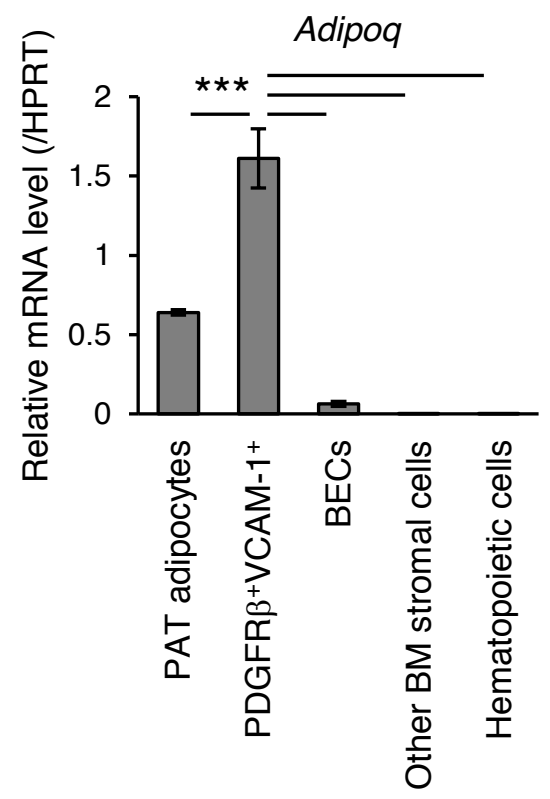

B

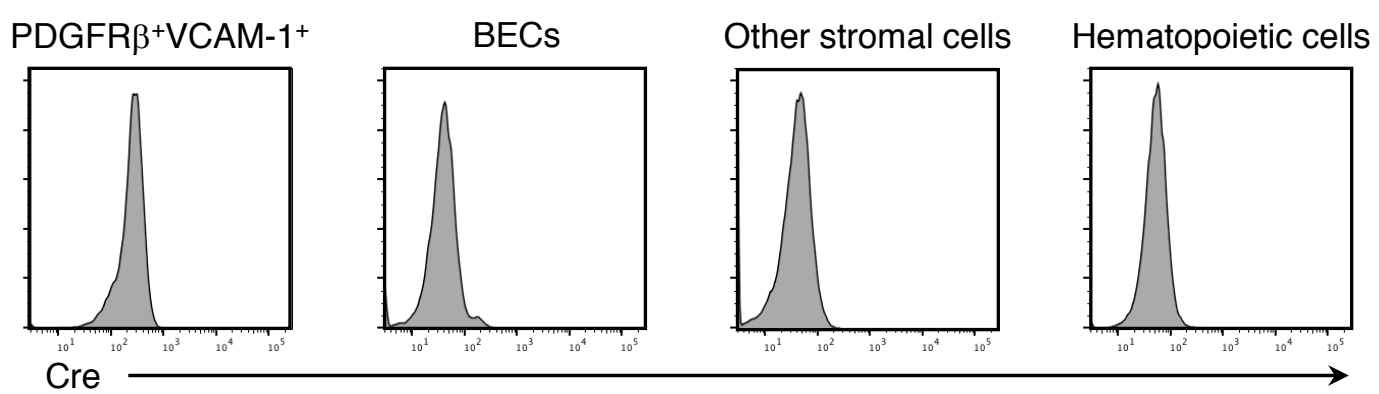

Overlaid histogram

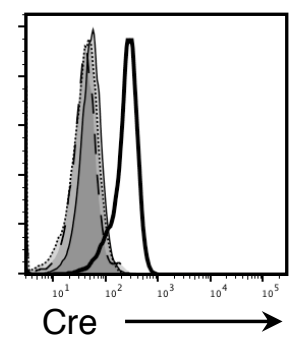

C

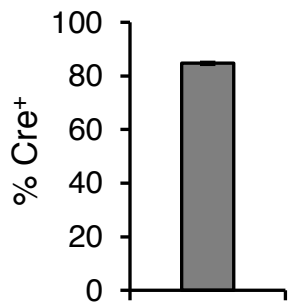

PDGFR $\beta+$ VCAM-1+ 
A. 京都大学ry FIGURE 2

Adipoq-Cre ${ }^{+;}$R26 $6^{\text {tdTomato }}$ Bone marrow

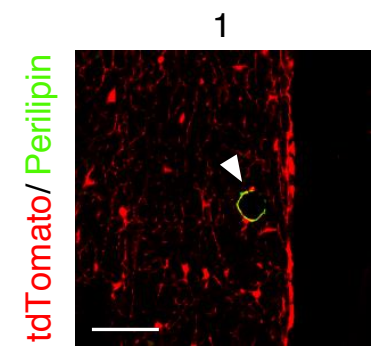

2

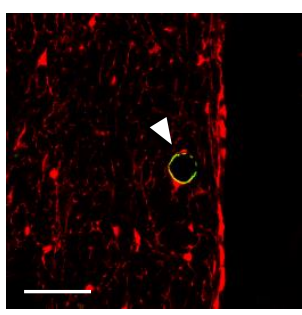

3

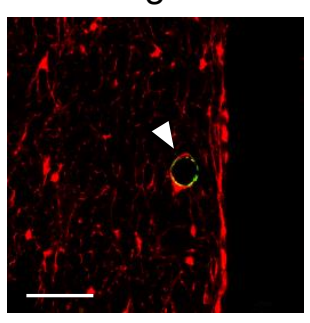

4

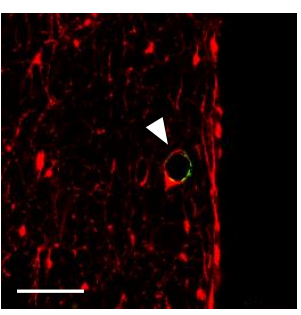

5

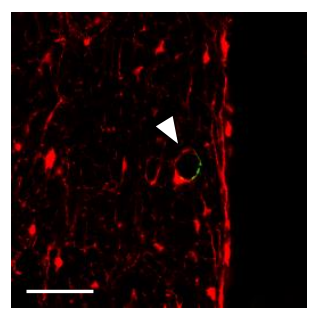


京都大学ry FIGURE 3

Adipoq-Cre+; R26 ${ }^{\text {YFP }}$ Bone marrow

Ter119-CD45-CD31-Sca-1-
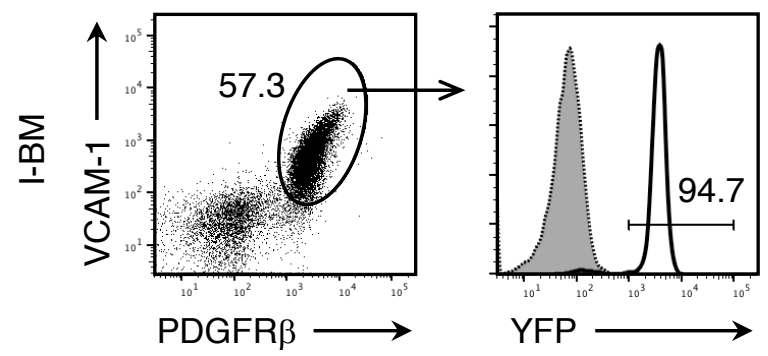

Ter119-CD45-CD31-Sca-1-
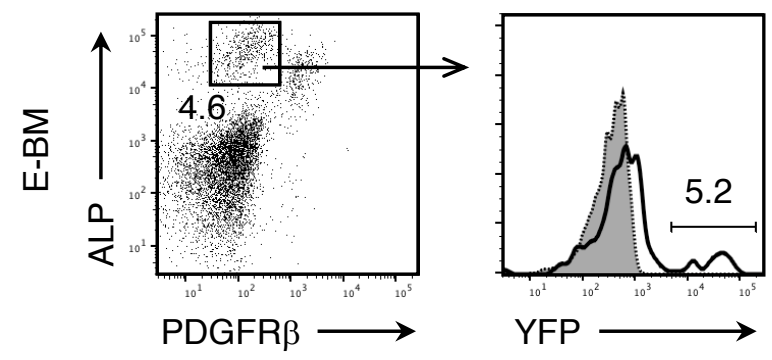

C Adipoq-Cre+; R26 ${ }^{\text {YFP }}$ Bone marrow
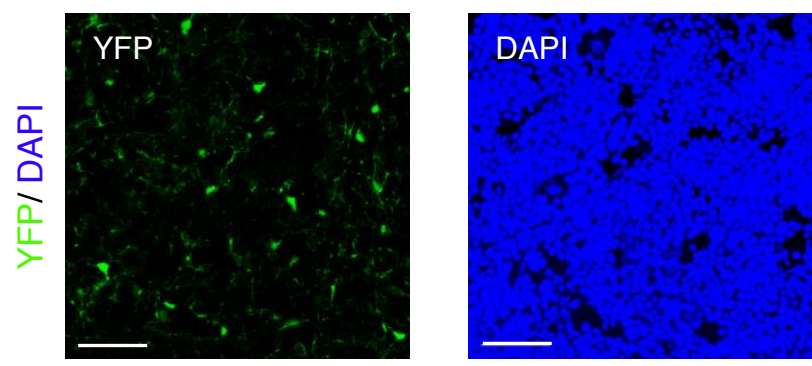

B

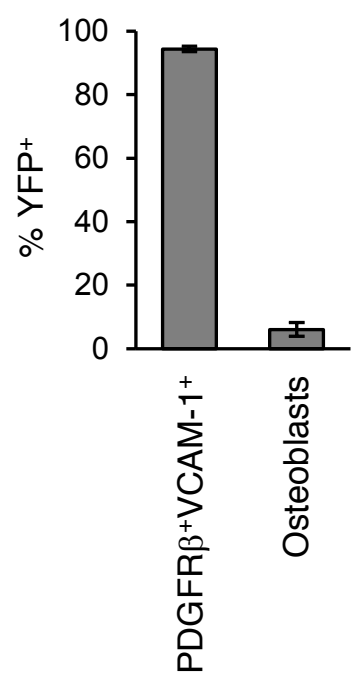

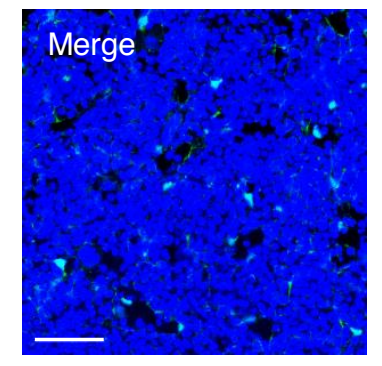


A 京都大学IY FIGURE 4

KYOTO UNIVERSITY

Adipoq-Cre+; R26 $6^{\text {tdTomato }}$ Thymus
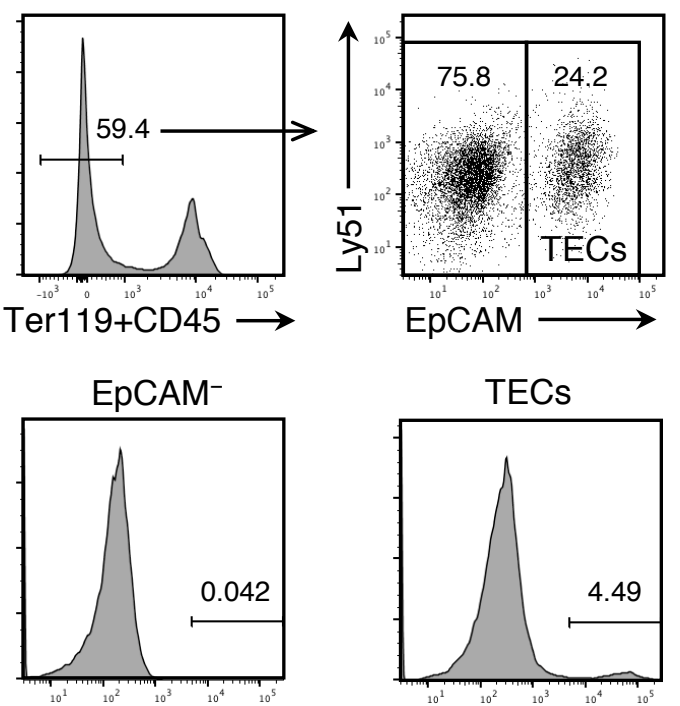

tdTomato

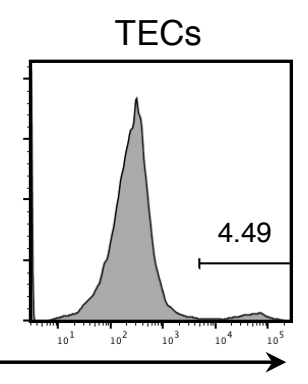

C Adipoq-Cre+; R26 ${ }^{\text {tdTomato }}$ Thymus

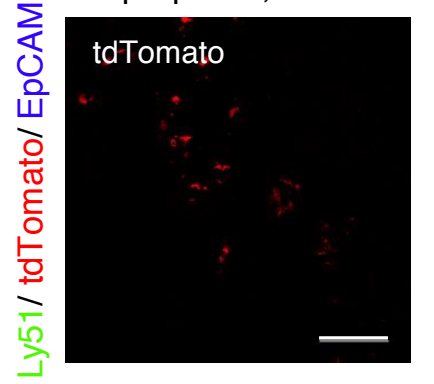

D

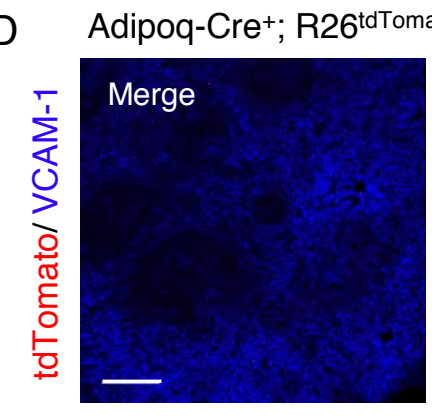

to Spleen

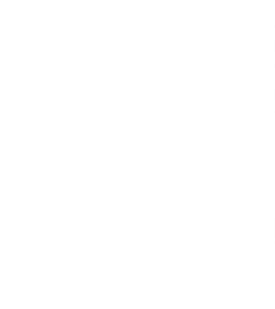

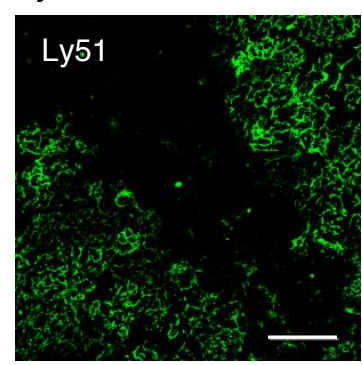
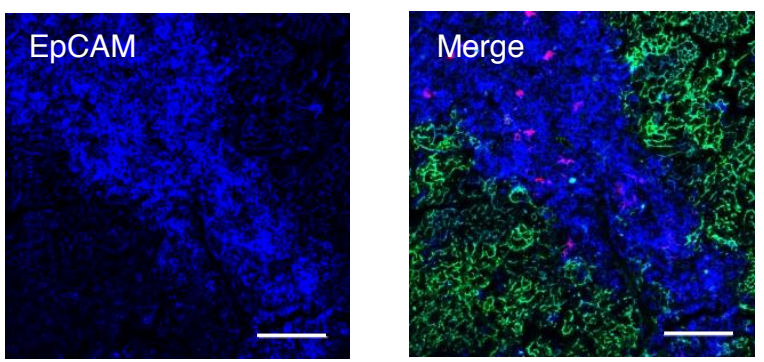

E Adipoq-Cre+; R26 ${ }^{\text {tdTomato }} \mathrm{mLNs}$

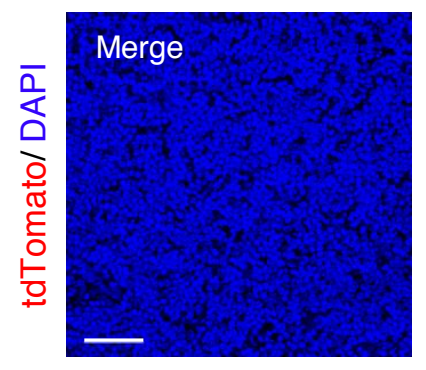

B

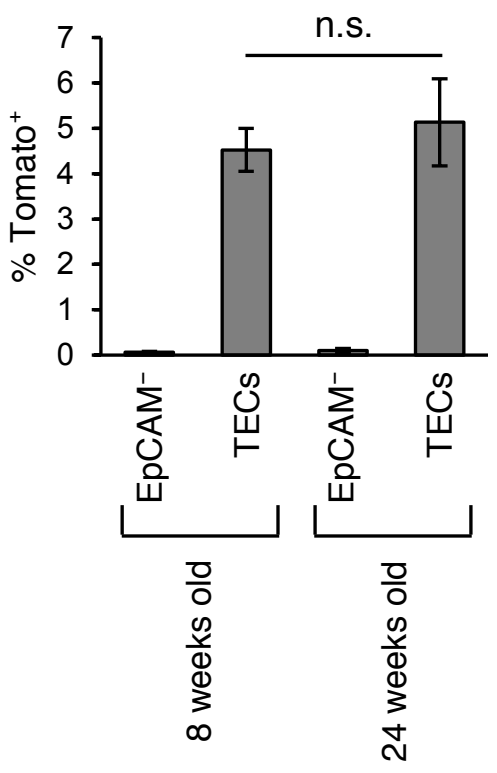


A Adipoq-Cre+; R26 ${ }^{\text {tdTomato }}$ Bone marrow

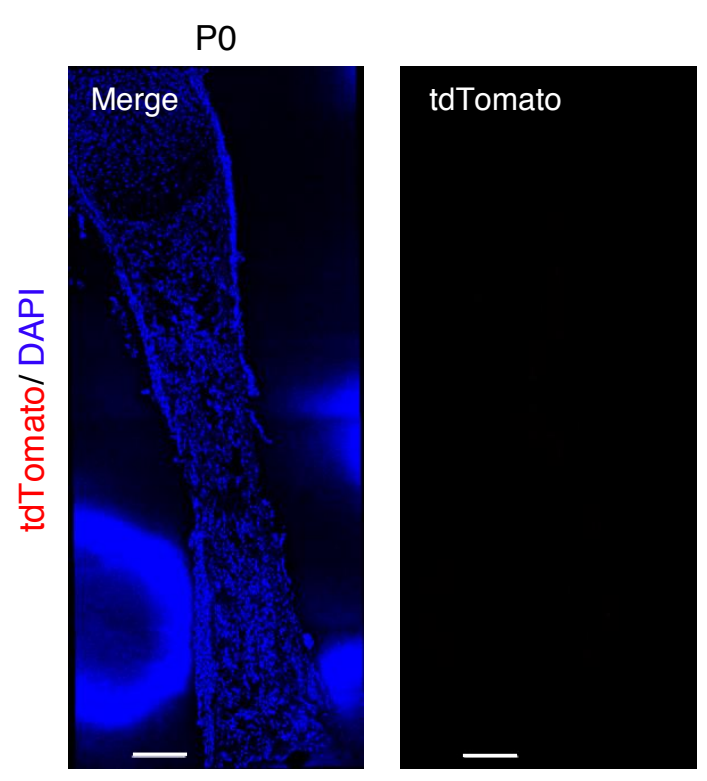

B Adipoq-Cre ${ }^{+} ;$R26 $^{\text {tdTomato }}$ Bone marrow

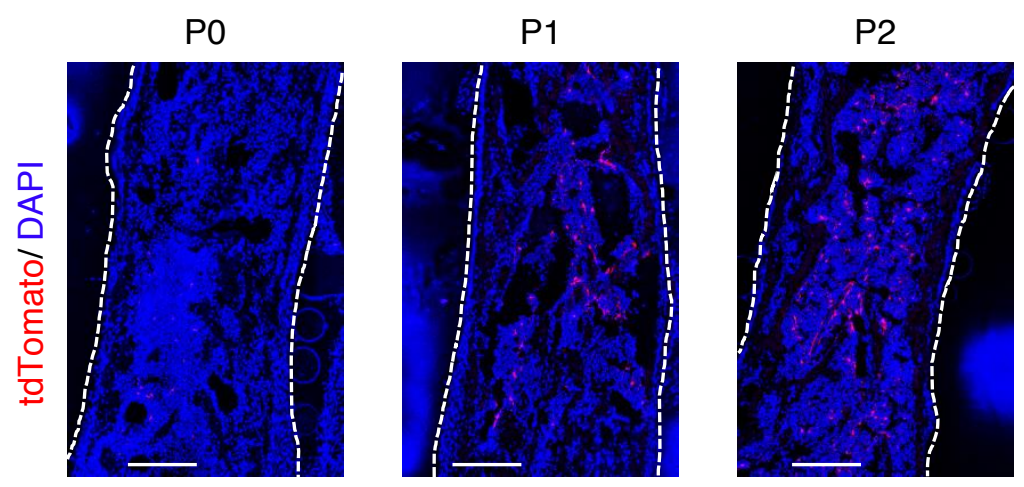


京都大学IVY FIGURE 6

A $\quad$ IL7 $7^{\mathrm{GFP} /+}$ Bone marrow

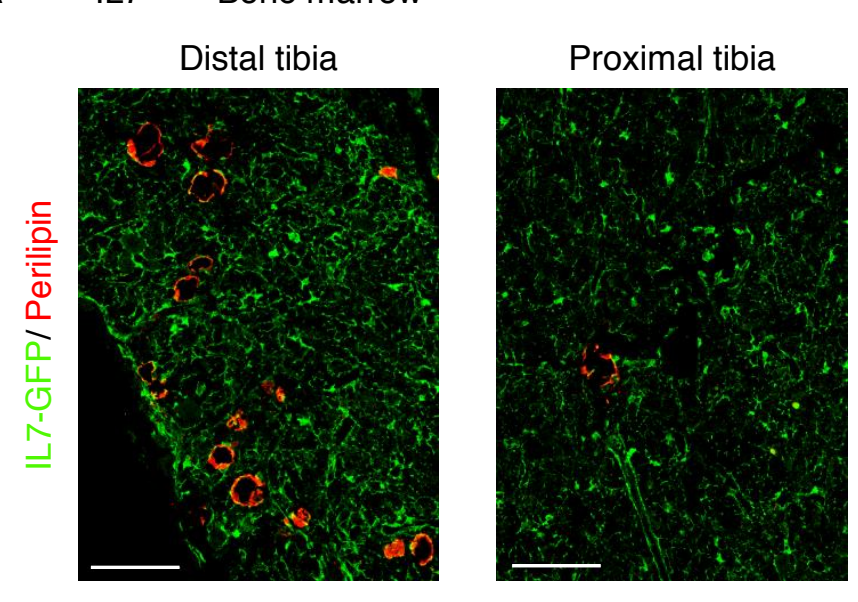

\section{Proximal tibia}

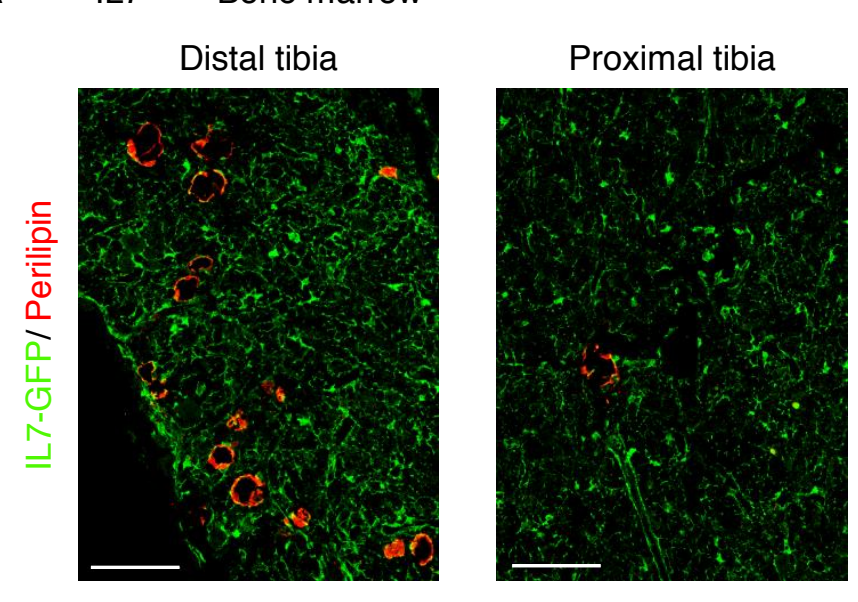

B

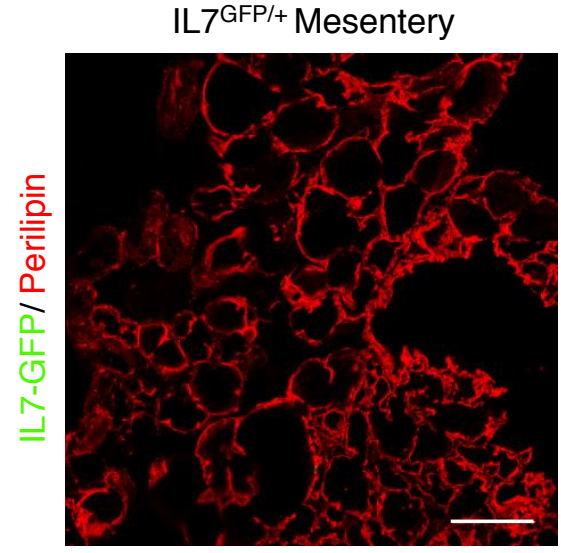
IL7 ${ }^{\mathrm{GFP} /+}$ Mesentery 
A

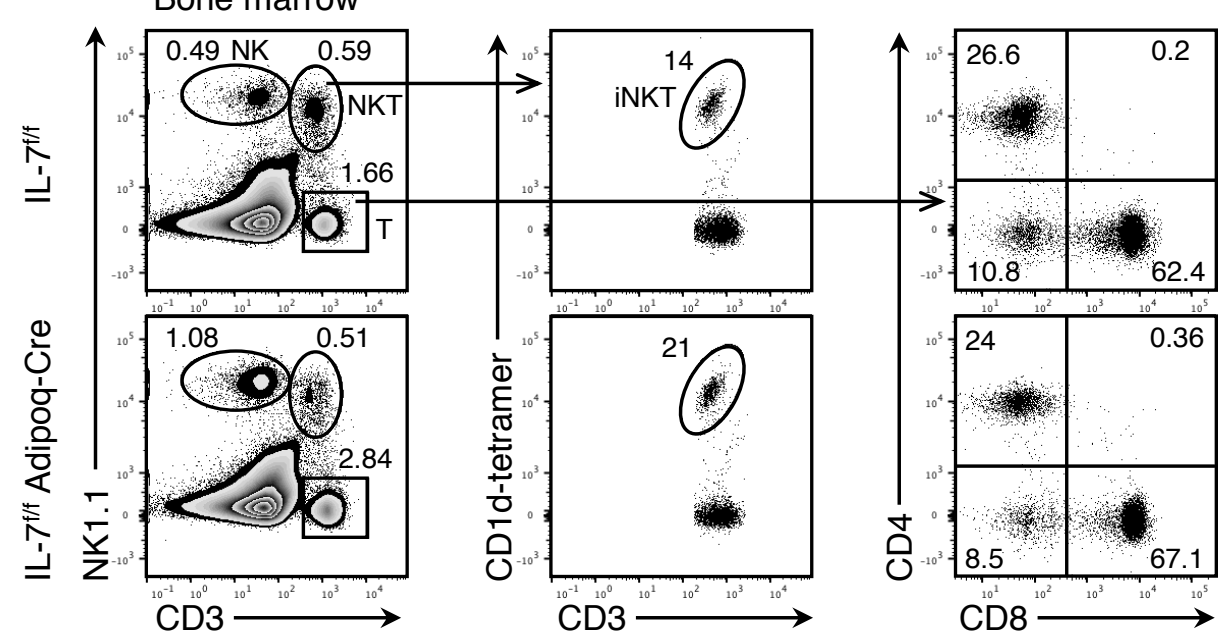

B
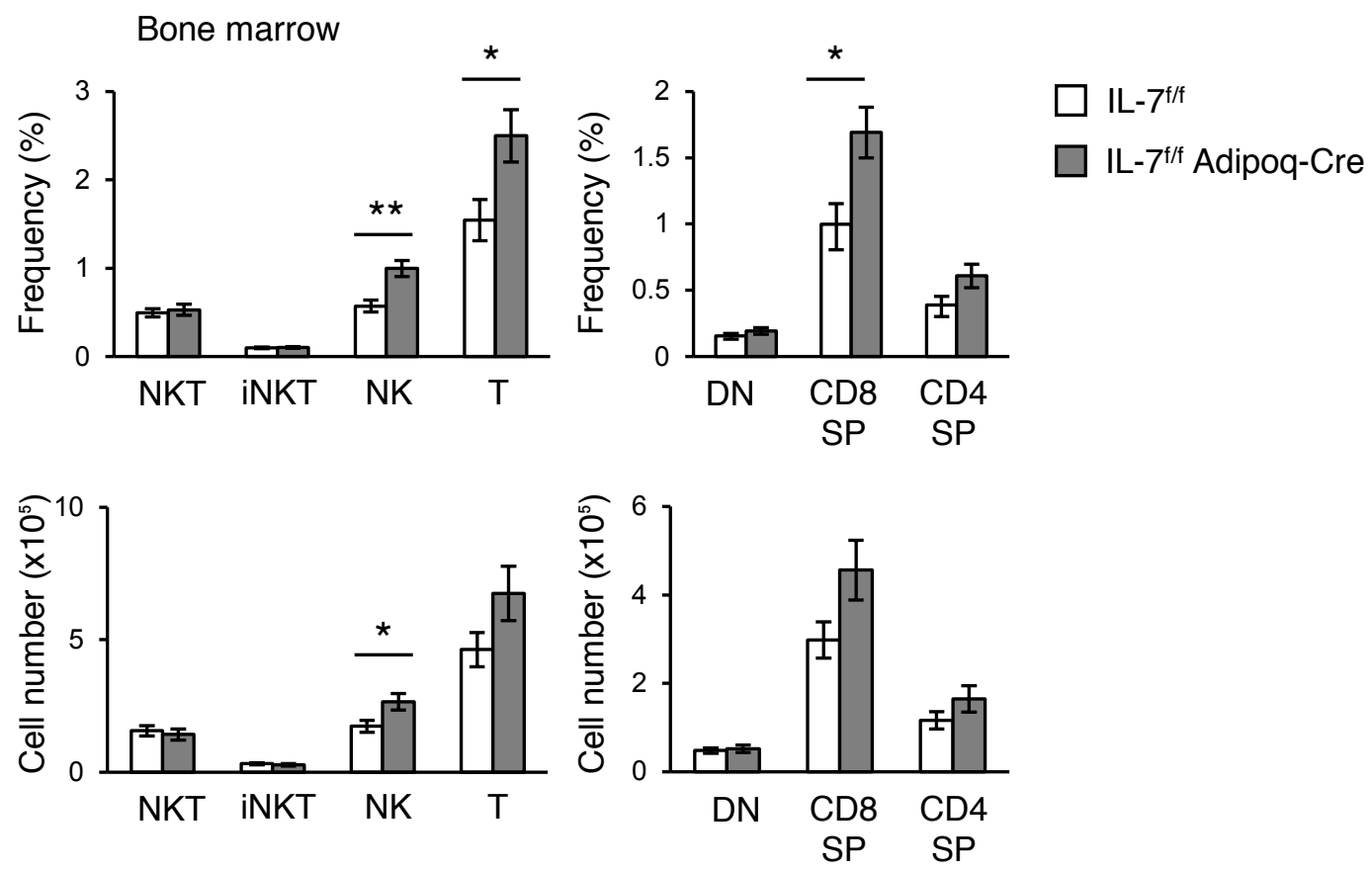


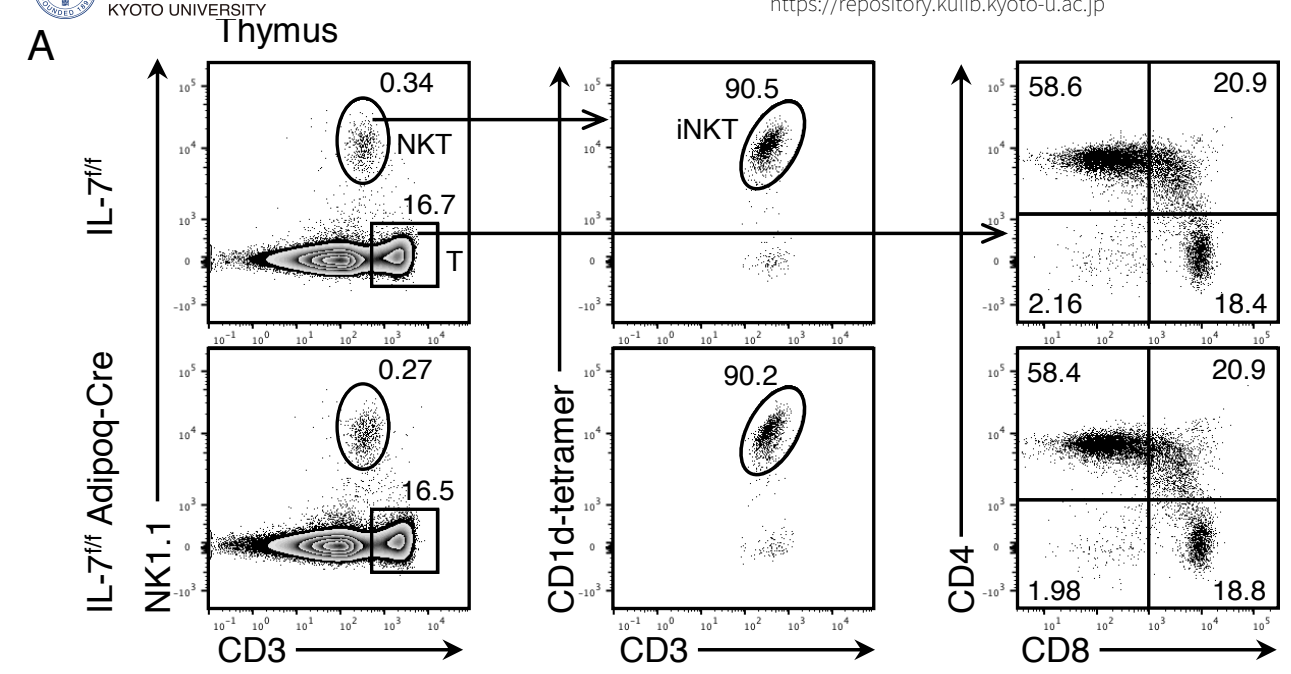

B

Thymus
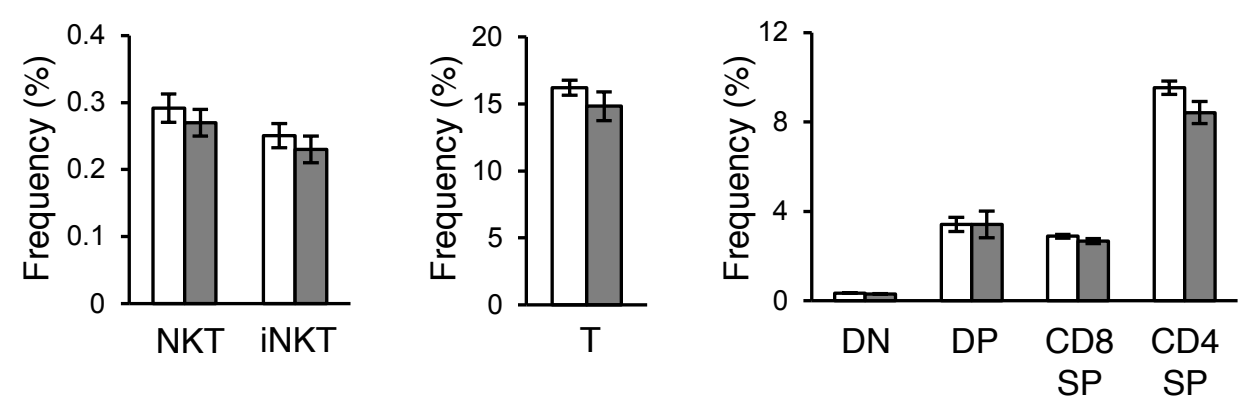

$\square \mathrm{IL}-7^{\mathrm{fff}}$

$\square \mathrm{IL}-7^{\mathrm{f} / \mathrm{f}}$ Adipoq-Cre
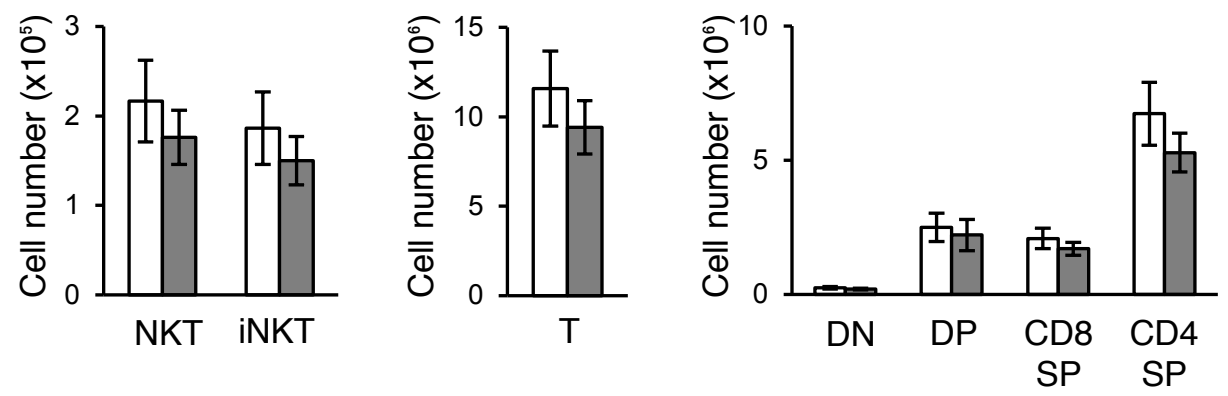
궁 都大学ry FIGURE 9

A Perigonadal adipose tissue

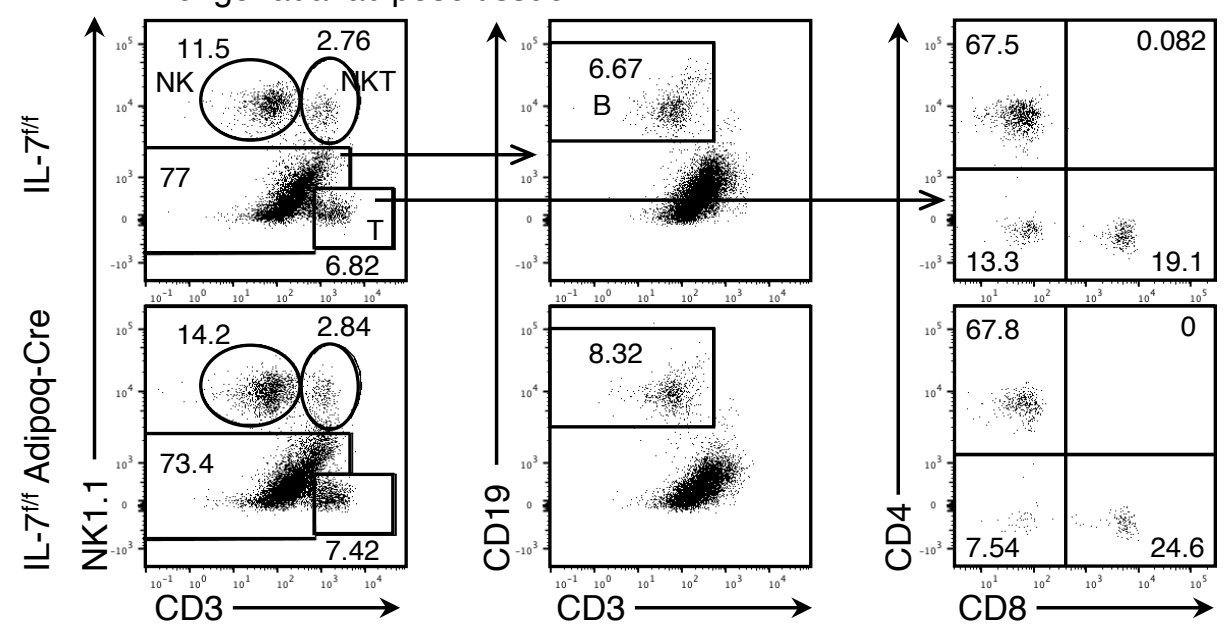

B Mesenteric adipose tissue

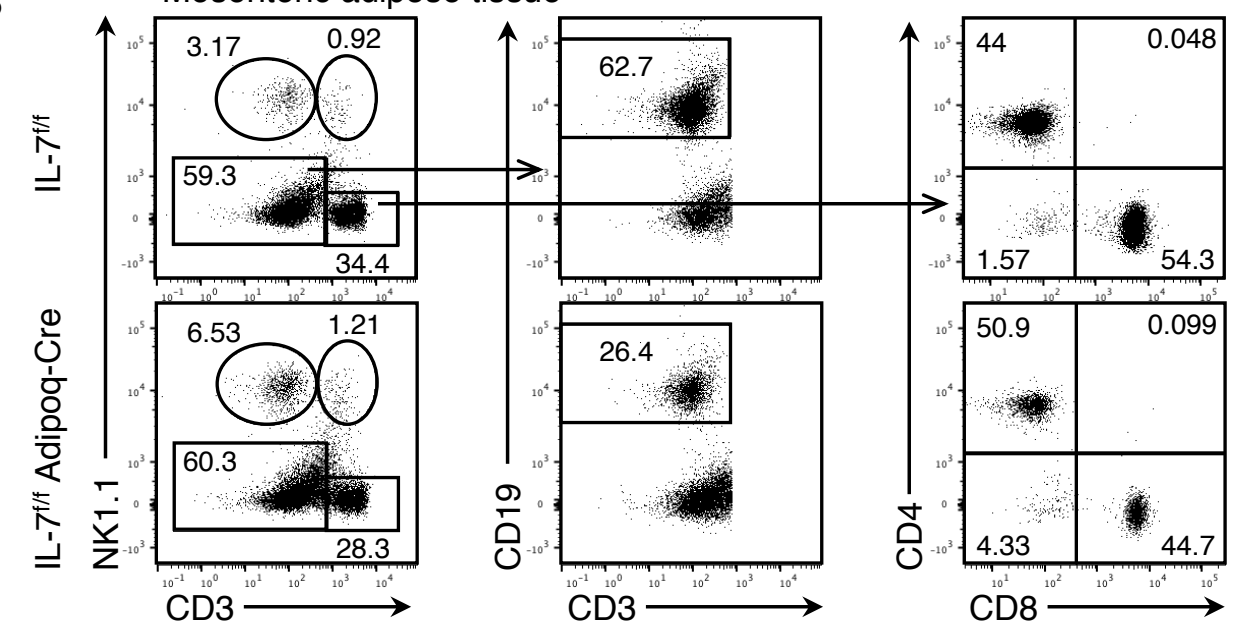

C Perigonadal adipose tissue
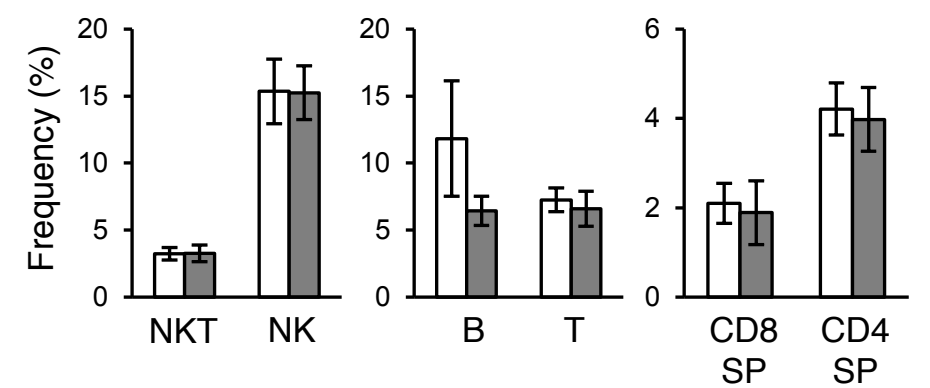

D Mesenteric adipose tissue

$\square \mathrm{IL}-7^{\mathrm{f} / \mathrm{f}}$
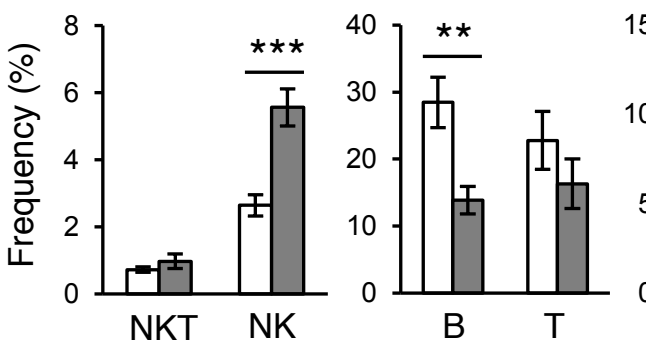

IL-7fff Adipoq-Cre
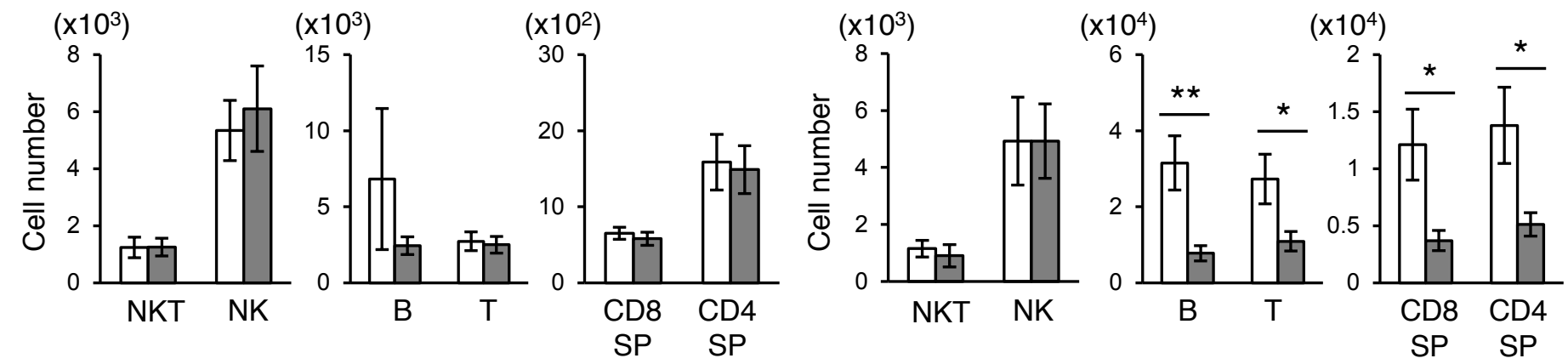
A Spleen

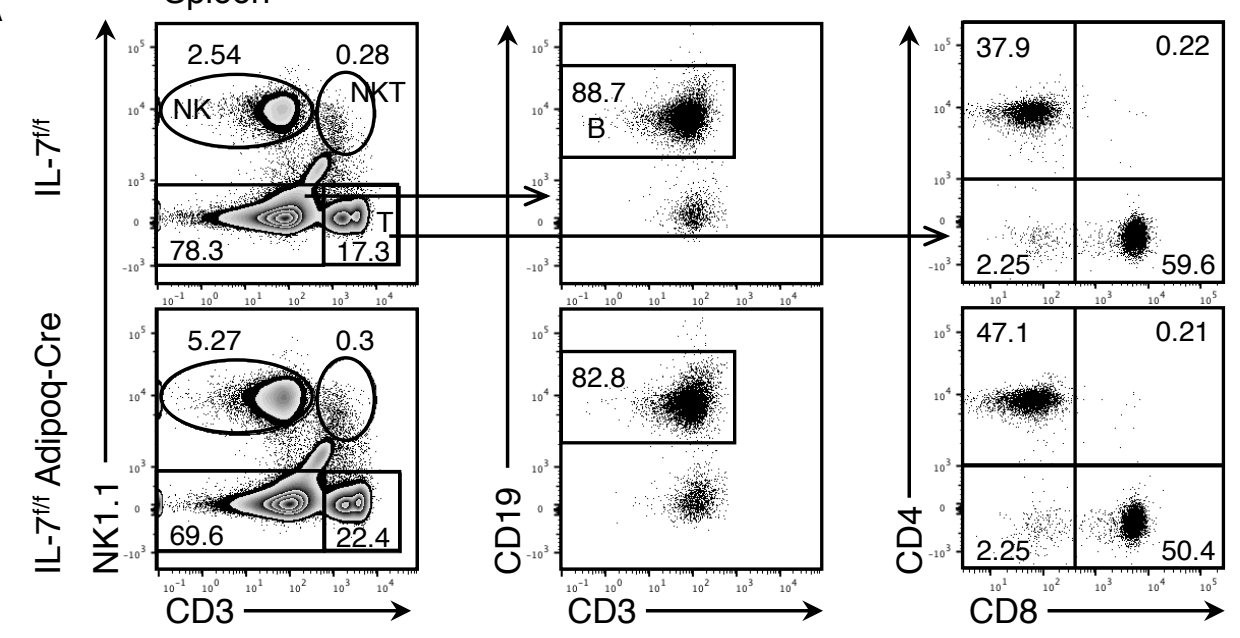

B Mesenteric lymph nodes

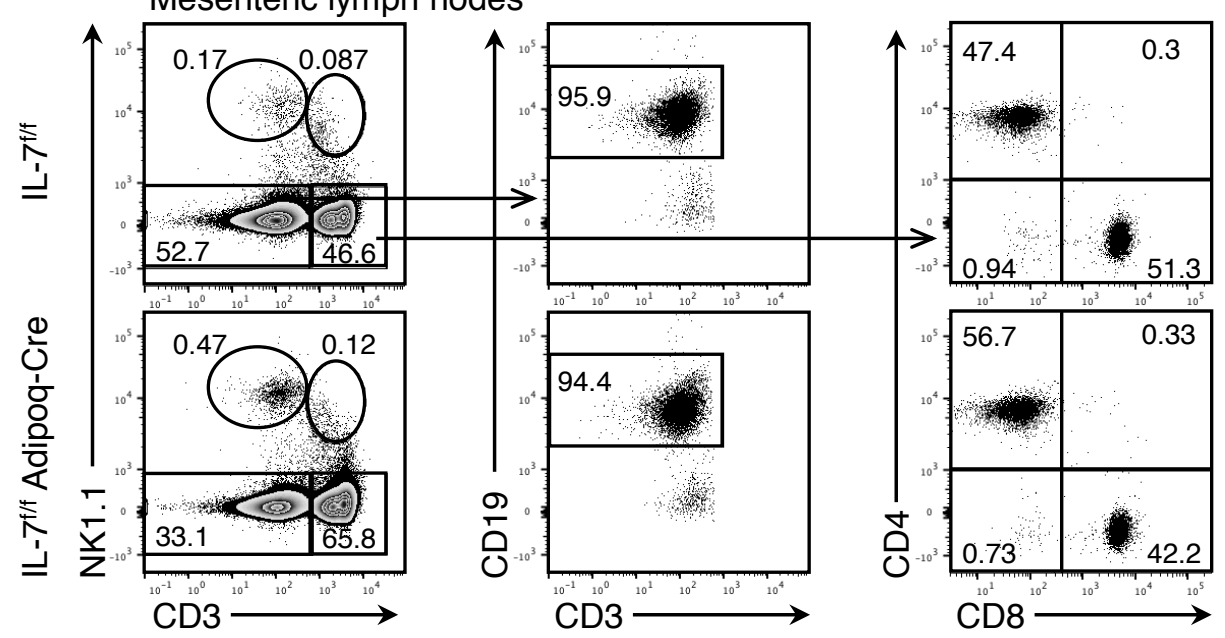

C Spleen

o

4े
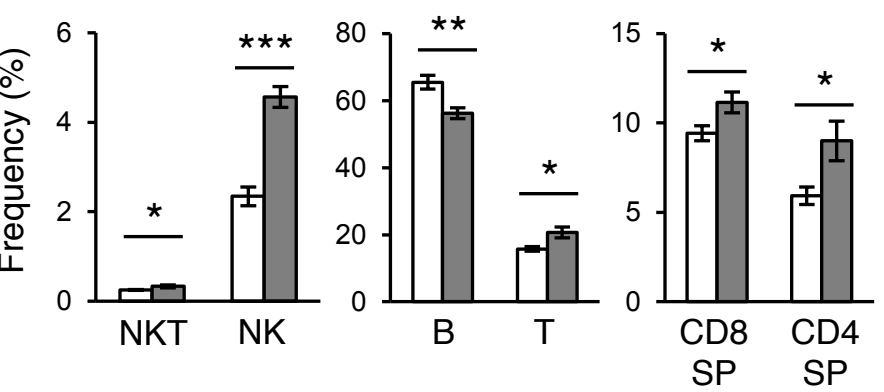

D Mesenteric lymph nodes

$\mathrm{IL}-7^{\mathrm{f} / \mathrm{f}}$
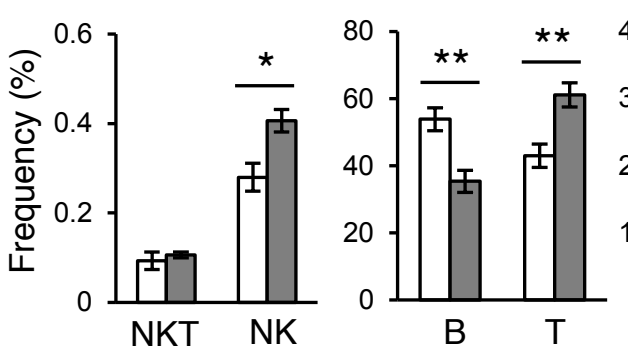

IL-7 $7^{\text {f/f }}$ Adipoq-Cre
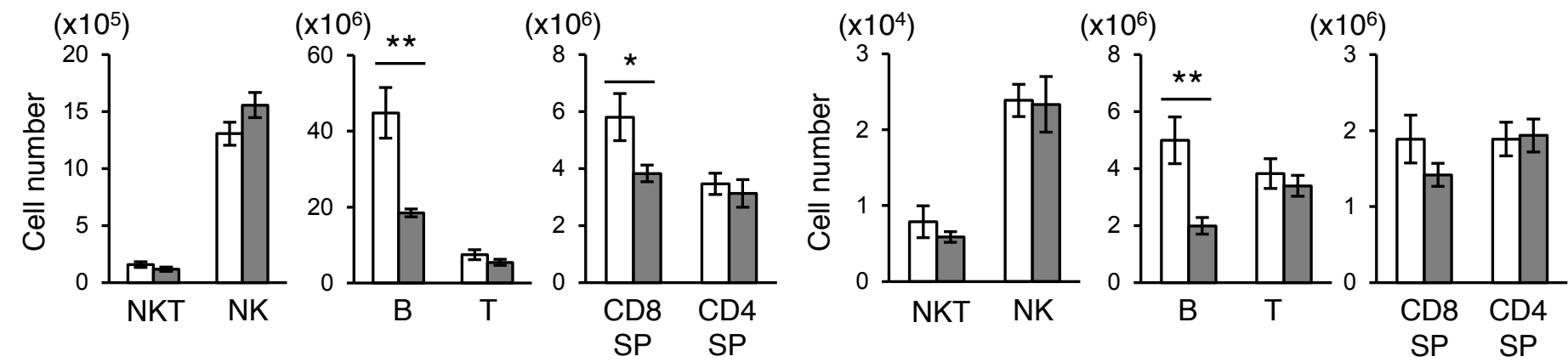